\title{
Trust no more? On the lasting effects of corruption scandals ${ }^{*}$
}

\author{
Albert Solé-Ollé, Pilar Sorribas-Navarro \\ UB \&IEB
}

\begin{abstract}
We examine whether the break out of a corruption scandal involving the incumbent undermines trust in government, and whether this effect fades in the short term or whether it has lasting effects. We use a novel dataset with information on local corruption scandals occurring in Spain in the period 1999-2009, and data on the level of trust expressed in local politicians, obtained from a survey conducted in 2009. We find that corruption scandals have a marked effect both on levels of trust in local politicians and on perceptions of corruption. We also show that, while these perceptions gradually revert back to their pre-scandal levels, the effect on trust is more persistent. Using a mediation analysis we show that other side effects of corruption (including, government fragmentation and fiscal stress) are responsible for the persistence of these effects on trust.
\end{abstract}

Keywords: corruption; trust

JEL Classification: P16, D72 
"The Watergate scandal had a devastating effect on American politics [...] Each revelation gave voters another reason not to trust their elected officials [...] Americans could never look at government the same way again."

- Julian Zelizer, CNN contributor. ${ }^{1}$

\section{Introduction}

Local corruption scandals provoke both astonishment and indignation among citizens, who vent their anger as news of the scandal breaks and the press disseminates the lurid details of each case. Images of the police raiding a town hall in search of evidence or arresting the mayor and other prominent local politicians abound these days on the front pages of newspapers across Spain - our case of study. ${ }^{2}$ Such stories tend to trigger an immediate reaction, as citizens express their feelings of distrust in local politicians on the street and in the social media. ${ }^{3}$ However, it is unclear whether such events are simply a nine days' wonder that are quickly forgotten or whether they have lasting consequences on political life. Both possibilities find some support in the literature. On the one hand, the research on the effects of corruption on voter behavior does find quite small effects, ${ }^{4}$ and attribute this to short voter memories, the reduction in media coverage over time, and general scandal fatigue. On the other hand, there is also some evidence that extraordinary events (e.g., wars, terrorism and other crises) have the potential to affect political attitudes in the future. ${ }^{5}$ The shock caused by such events seem capable of changing beliefs and/or convictions, which accounts for their permanent effect on political attitudes. The quotation citing the 'devastating effects' of the Watergate scandal that opens this paper suggests that major, unexpected corruption scandals may well have similar effects.

In this paper we seek to shed light on this issue by studying whether corruption scandals affect trust in government and perceptions of corruption and whether these effects fade rapidly or whether they have lasting effects. Our results suggest that the break

\footnotetext{
1 "Distrustful Americans still live in age of Watergate", edition.cnn.com, 07/07/2014.

2 A rapid search in Google reveals hundreds of such stories. See, e.g., "The police register Tarragona City Hall offices" (El País, 9/09/2015), or "The mayor of Alacanar and his urban planning councilor arrested for corruption" (El País, 16/10/2014).

3 See "Anti-corruption demonstration in Valdemoro" (El Mundo, 8/11/2014) or "The mayor of Estepona booed on arriving handcuffed at the town hall" (20minutos, 17/06/2008).

${ }^{4}$ See, e.g., Peters and Welch (1980), Dimock and Jacobson (1995), Welch and Hibbing (1997) and Chang et al. (2010), for several countries; and Costas et al. (2012), Barberá et al. (2013), Fernández-Vázquez et al. (2015), specifically for Spain.

${ }^{5}$ For example, there are several papers that show this to be the case of political partisanship (see e.g., Kaplan and Mukand, 2014), and interpersonal trust (e.g., Blattman, 2009, and Cassar et al., 2013).
} 
out of a corruption scandal has a statistically significant and sizeable effect on trust in local politicians and on corruption perceptions. However, while the perception of corruption recovers (albeit slowly) after the scandal, the effect on trust seems to be rather persistent. We explore this issue further by conducting a mediation analysis. This shows that the perception of corruption is an important mediator of the effect of corruption on trust. It also shows that the other side effects of corruption (e.g., increased government fragmentation and induced public finance problems) are the factors that account for the persistence of its effect on trust.

Our analysis relies on a very rich database that provides information on all local corruption scandals that broke out in Spain during the period 1999-2009. This database was previously used by Costas et al. (2012), but has been updated for this project. We combine this information with individual data on trust in local politicians obtained from a survey that we commissioned in 2009. This survey was carried out on a matched sample of corrupt and non-corrupt municipalities selected from the corruption database described above. Care was taken to select a sample that is representative of the cases reported in the different years. This has allowed us to examine the effects of the time elapsed between the scandal and the survey.

To address concerns about selection into the corruption status, we employ several strategies. First, we use a selection on observables strategy. The fact that we obtain our trust and corruption perceptions data from a survey that we conducted on a matched sample of corrupt and non-corrupt municipalities guarantees that municipalities with and without corruption scandals are very similar as regards various relevant observable characteristics. This means any differences between them can be attributed to the 'treatment' (Rosenbaum and Rubin, 1985, and Ho et al., 2007). Second, following Imbens (2003), we perform a sensitivity test to determine how big the effect of a potentially omitted variable would have to be to undermine our results. Third, we also rely on falsification tests (see Heckman and Hotz, 1989; Rothstein, 2010). Our main falsification test uses data on corruption scandals that occurred after the survey was conducted. Using this additional data, we find that only the scandals that broke out before the survey had a negative and significant effect on trust.

Our paper contributes to the literature on the effects of corruption on trust in government in three ways. First, we improve the robustness of the methodology by employing a research design which deals with the endogeneity problems that typically affect such studies. Most previous papers use individual responses to questions on 'perception of corruption' and 'statements of trust' in government originating from the 
same survey (Seligson, 2002, Chang and Chu, 2006, Morris and Klesner, 2010). Using such data it is quite likely that the relationship found is spurious. Some papers tackle this issue by employing contextual measures of corruption, such as those provided by Transparency International (Anderson and Tverdova, 2003), while others rely on corruption scandal data (Bowler and Karp, 2004; Kumlin and Esaiasson, 2012). We also adopt the latter approach; however, we believe that our research design, while still being observational, constitutes an improvement on designs used in the prior literature. Specifically, we are not aware of any paper in the literature that has used a falsification test based on the misalignment between the time of the scandals and the time of the survey.

The second contribution is the analysis made of the dynamic effects of corruption on trust. Although the effects of corruption scandals are likely to be lasting in time, none of the papers in this literature examines this issue. There are some studies in the field of political communication focus on the very short run effects - i.e., days, weeks or months - of news' framing on political knowledge (Elenbaas and De Vreese, 2008), trust in specific politicians (Kleinnijenhuis et al., 2006) and political cynicism (Bruter, 2009); however, we believe this to be too narrow time span for the case we seek to examine. The literature on the effects of other types of shock on political participation or attitudes (e.g., Blattman, 2009, and Cassar et al., 2013) focuses on a longer period (e.g., decades), a time span that we consider more appropriate for our purpose. Finally, we investigate several mechanisms (corruption perceptions and political fragmentation, among others) that could explain why corruption erodes trust and why the effect is lasting.

The rest of the paper is organized as follows. The next section outlines a simple theoretical framework that helps us discuss why the effects of corruption scandals on trust might persist over time and what role is played by corruption perceptions and other possible mechanisms. Section three provides background details for the analysis reported here. It describes the recent surge in local corruption scandals in Spain and current discussions as to how this affects trust in government and the legitimacy of democratic institutions in the country. Section four describes the data and the methodology. Section five presents the results. The last section concludes.

\section{Theoretical discussion}

There are several mechanisms that might account for the effect of corruption scandals on trust in government, each operating over a specific time horizon. The first possibility is that exposure to information about corruption (e.g., media coverage) accounts for the effect on political knowledge (Elenbaas and De Vreese, 2008) and, as a result, on levels of 
trust in politicians (Kleinnijenhuis et al., 2006). Hence, the suggestion is that the impact of a scandal on trust might be mediated by perceptions of corruption. There is also evidence that voters tend to forget events of this type (Costas et al., 2012), lose interest due to fatigue (Kumlin and Esaiasson, 2012), and that media coverage eventually diminishes as fresh events appear (Eisensee and Stomberg, 2007). This suggests that the impact of a scandal might not last long. However, there are motives to believe that the effect might be more persistent. First, in new democracies, where voters have high expectations and no experience of local corruption, ${ }^{6}$ a scandal might cause a permanent shift in beliefs about the degree of corruption of the entire local political class (Mishler and Rose, 1997). Second, the impact of a scandal might diminish temporarily, but the speed and intermittent nature of the judiciary's actions might bring it to the public attention again. ${ }^{7}$ Likewise, other scandals in the country might remind voters of the situation in their own town. As such, the impact on corruption perceptions and on trust might lie 'dormant' (Bruter, 2009).

The second possibility is that the corruption scandal triggers many side effects, not directly related to the increase in the perception of corruption. Here the possibilities are manifold, so we discuss the three we consider most plausible in our case. First, the scandal might generate an increase in political fragmentation. This might happen for several reasons. For example, voters might cease to support the incumbent and choose other parties. Often they will support the main opposition party but sometimes they will opt for smaller and less well-established parties. New parties may enter the political arena with an anti-corruption platform. Old parties might split because of the scandal, one faction staying with the politician accused of corruption. The result might be an increase in the number of non-majority governments and a more fragmented council. The consequences of which might be an increase in the frequency of government crises and policy gridlock, which could manifest itself, for example, in a greater difficulty in passing budgets on time (Mian et al., 2014). There is evidence that policy inefficacy - and not just malfeasance has an adverse effect on trust in government (see e.g., Hetherington, 1998). And we might even hypothesize that conflict inside the council could also reduce trust in the institutions. ${ }^{8}$ The effect of the scandal might not be instantaneous, as it can take time for

\footnotetext{
${ }^{6}$ As we explain in the following section, local corruption scandals in Spain had been very rare since the restoration of local elections in 1979.

${ }^{7}$ Complaints about the speed of the judicial system in dealing with corruption scandals are commonplace in Spain. See, e.g., "The slow pace of justice”, El País 02/02/2013.

8 It is not rare that a local corruption scandal in Spain results in a 'motion of no-confidence', leading to the fall of the government. Sometimes the new coalition includes turncoat representatives. All
} 
the political actors to realign (i.e., new parties to organize and become a viable alternative), suggesting that the effect on fragmentation might grow over time.

Second, a corruption scandal might also affect a municipality's public finances. For example, it can lead to cuts in grants from higher tiers of government. There is evidence that this is the case in Brazil where the federal government appears to use grants to reward/punish local performance (Brollo, 2013). ${ }^{9}$ This fall in revenues can have a significant impact on the local budget. If capital projects are already under way, it might be difficult to immediately downsize the spending budget, which means that taxes and/or deficits will have to rise. ${ }^{10}$ This could be interpreted by voters as indicative of bad performance and, thus, erode trust. In practice, the effect on public finances might be denied for some time (i.e., deficits could be hidden and tax hikes delayed) meaning that the effect of corruption on fiscal stress (and accordingly on trust) might be increasing over time.

Third, corruption might affect economic development. The type of corruption studied here (see next section) involved primarily the acceptance of bribes in exchange for development rights and building permits. This means that corruption might have gone hand in hand with development and so the impact on the economy might remain positive after the scandal if there is some inertia in the system. There is evidence for the USA that trust in government might be influenced by the state of the economy (see Hetherington and Rudolph, 2008). In fact, in the Spanish case, there is evidence that the electoral impact of corruption is not as great when voters perceive corruption to have a positive effect on the local economy (Fernández-Vázquez et al., 2015).

In short, a corruption scandal might erode trust in government because it changes voter perceptions of just how corrupt local politicians are or because it can have major side effects on the town's economy and political life. Depending on the case, the impact on the perception of corruption may become either weaker or stronger over time. The actual

this generates considerable conflict and political life in the town suffers accordingly. There are multiple accounts of this; see, e.g., "The PP presents a motion of no-confidence in the mayor of Leon with the help of two turncoat representatives", El País, 23/11/2004.

${ }_{9}$ There is also some evidence from Brazil that tax compliance drops after a corruption scandal, as information about corruption has a negative effect on 'tax morale' (Garfías and Timmons, 2015). Unfortunately, we do not have the data needed to investigate this mechanism.

10 There is considerable anecdotal evidence suggesting that during the last housing boom in Spain some local governments initiated capital projects based on the expectations of a future stream of revenues (including both developer revenues and capital transfers). 
dynamic effect of the scandal on trust, therefore, will depend on the interplay of all these factors.

\section{Corruption scandals in Spain}

\subsection{The recent surge in corruption scandals}

In the first two decades following the restoration of Spain's democratic local governments (1979-99), little concern was expressed in the media, among the political elite, or among the population in general, about its lack of accountability or about possible cases of corruption (see Jimenez and Caínzos, 2003). This was to change after 1995, however, as a result of events in a booming housing market, but it did not actually make itself manifest until 1999. Before that year, there had been just 46 local corruption scandals, but by 2003 this number had risen to 211 (for the 1999-2003 period). In the years up to 2007, a further 215 scandals were reported, while in the period that ran from the June 2007 local elections to November 2009, 131 new cases emerged. ${ }^{11}$ Since that date, the collapse of the housing market has reduced opportunities for corruption. Yet, the public, the media, and the judiciary have been especially sensitive to corruption during the crisis, so that a substantial number of scandals involving earlier corrupt acts have come to light in recent years. $^{12}$

\subsection{Corruption in land use regulations}

Most of the local corruption scandals that broke out in Spain in the recent past have involved politicians accepting bribes in exchange for amendments to the land use plans and building permits (Fundación Alternativas, 2007). Land use regulations in Spain are governed by a highly interventionist and rigid system (Riera et al., 1991) and most town planning responsibilities are in the hands of local governments. As such, municipalities draw up a 'General Plan', which provides a three-way land classification: built-up land, developable land, and non-developable land. The existence of a 'development border', a line between plots of land on which developers are allowed to build and plots where development is prohibited, is a key feature of Spain's land regulation system. In periods of high demand this border creates a rent differential, which might fuel the bribes developers are willing to pay to local politicians in exchange for shifting this border to their advantage (Solé-Ollé and Viladecans-Marsal, 2012). Although land planning is

\footnotetext{
11 The data comes from Costas et al. (2012); see next section for details.

12 Although we do not have good quality data on the scandals that broke out after 2009, it is estimated that the number of cases could have reached 800 by 2013 , based on reports in the Spanish press ("Number of corruption cases reaches 800 in a decade", El País, 17/06/2013).
} 
subject to participatory and transparency requirements, in practice local incumbents readily find ways of circumventing them. It is this combination of discretionary decisions and the lack of transparency that fuelled the recent surge of corruption scandals in land use regulations in Spain. Most of these scandals have involved local officials wrongfully allowing huge tracts of land to be developed, permitting building to go ahead in places where it had been previously prohibited, or amending the land use plan so as to permit higher construction densities on already developed land (Fundación Alternativas, 2007).

\subsection{Corruption, voting, and disaffection}

In Spain, it is generally held that corrupt politicians are not punished at the polls. The press has provided intensive coverage of some highly prominent scandals, and yet those accused of corruption have been re-elected. Several studies conclude that the average punishment is quite low (i.e., around 3-4\% of the vote) (Fundación Alternativas, 2007, and Barberá et al., 2013), although other studies suggest this effect may, on occasions, be higher (Costas et al., 2012; Anduiza et al., 2013), depending on such factors as the quality of media information, the intervention of the judiciary, the existence of clientelistic networks, and the degree of political polarization. There has also been considerable debate about the possible adverse effects of corruption on trust. For example, in $2010 \mathrm{a}$ prominent think-tank entitled its annual report "The erosion of confidence and well-being. Against citizens' disaffection" (Fundación Alternativas, 2010). The report warned about the possible long-term effects of corruption on trust in government and on legitimacy of democracy. ${ }^{13}$

Dissatisfaction with politics in Spain also spiralled as corruption spread from the local to higher levels of government. Concerns that the perception of widespread corruption at the national level may spill over and affect evaluations of the corruptibility of politicians might, therefore, be justified. However, we do not believe this to be especially problematic for the period we study. Evidence supporting this claim is provided by data from the Centro de Investigaciones Sociológicas, which show that until the very end of 2009 , corruption had only been perceived as a problem by a tiny proportion of the Spanish population. Figure A.1 in the Appendix reports the share of the population that identified corruption as being among Spain's three main problems. When the survey was conducted, only $2 \%$ of the population considered corruption to be one of the three main problems in Spain. The emergence of corruption scandals at the regional and national

\footnotetext{
13 The report also cited the inaction of political parties, the partisanship of the media, and the lengthy operation of the judiciary, as possible reasons for this increase in dissatisfaction.
} 
level and the deepening of the economic crisis substantially increased these concerns in a brief period of time. ${ }^{14}$

\section{Empirical analysis}

\subsection{Measuring corruption and trust}

\subsubsection{Local corruption}

Corruption scandals are measured here as cases of corruption covered in the Spanish press with at least one news story. To obtain information on these scandals we employed a database compiled by the Spanish think-tank, Fundación Alternativas (2007). In 2007, following the surge in corruption scandals during the previous year, this organization commissioned a local corruption survey to gauge the quantitative relevance of the phenomenon. They hired a journalist in each Spanish province and gave them the task of compiling all the news items referring to corruption scandals in the municipalities in that province. The journalists recorded all corruption-related news stories in the national, regional and local press between 1 January 2000 and 1 February 2007. Overall, a total of 426 corruption scandals were reported during this period. This database has previously been used in Costas et al. (2012).

Given that our own survey was carried out in 2009, we completed the database for the intervening years with internet-guided searches conducted in MyNews, a paid digital information management service covering all national and many of the regional newspapers. We screened the period that runs from 1 February 2007 to 2 November 2009 (the day this search was performed). We found 131 additional scandals in this period, giving a total of 557.

Our database also provides information about the coverage given to the scandal in the Spanish press. Thus, we know the total number of news items published over the period and their distribution over time. This information allows us to examine the mediating effects of the distance between the first reports of the case and the date when the survey was conducted.

\footnotetext{
14 The share of respondents concerned about corruption evolved as follows: 3.2\% in March 2010, 4.6\% in March 2011, 12.2\% in March 2012, 44.5\% in March 2013 and 41\% in March 2014.
} 


\subsubsection{Trust in local politicians}

Our measure of trust at the municipal level comes from a survey we specifically designed to measure levels of trust as well as other aspects of citizen attitudes and reactions to local corruption. ${ }^{15}$ The survey was conducted on a sample of residents in a given fraction of the municipalities in which a corruption scandal had been reported between 1999 and 2009, as well as in a number of municipalities with similar traits to those affected by corruption but which remained corruption free. The survey was undertaken during fall 2009. Respondents were asked the following question at the beginning of the survey:

'In the case of your city, do you think politicians in the local council can be trusted?' Interviewees could respond by selecting one of the following four alternatives ${ }^{16}$ :

(1) 'Local politicians can never be trusted'

(2) 'Local politician can almost never be trusted'

(3) 'Local politicians can be trusted most of the time'

(4) 'Local politicians can always be trusted'

These four categories were used so that individuals would have to indicate whether they had a high or low degree of trust, but they were then able to fine-tune their response. The proportions of individuals selecting each category were: 23.0, 33.6, 33.5 and 9.9\%, for categories (1) to (4), respectively.

This question is the standard question used in similar surveys, including the European Social Survey. A possible concern in our case could be that respondents might not associate the question with local politicians (that is, with politicians in their own municipality), but rather with politicians in general. Were this to be the case, the levels of trust reported in corrupt and non-corrupt municipalities would be more similar than expected, and the treatment effects that we estimate might be biased downwards. To avoid this, the question begins 'In the case of your city...' and specifically enquires about politicians 'in the local council', while the responses also refer to 'local politicians'. A further concern is that the question might be too generic, in the sense that it does not ask whether a specific local politician can be trusted. However, most of the corruption scandals involve the mayor or politicians appointed to the executive by the mayor and these tend to be the best known local politicians. This means that we can expect the

\footnotetext{
${ }^{15}$ A detailed description of the structure of the survey can be found in the Appendix, Box A.1.

${ }^{16}$ An additional category 5 (Don't know - No answer) was included, but following standard procedures we do not use these responses in our analysis.
} 
respondents to associate the 'politicians in the local council' and the 'local politicians' with these particular politicians. ${ }^{17}$

The survey also included questions about the socio-economic characteristics of the individuals. These are used both as controls in the estimation and also to design several falsification tests based on subsample analyses.

\subsubsection{Corruption perception}

Information about perceptions of corruption comes from the same survey. Respondents were asked the following question:

"In the case of your city, what is your perception about the level of corruption of politicians in the local council?"

Interviewees could respond by selecting one of the following four alternatives: 'The level of corruption of local politicians is': (1) 'Low', (2) 'Medium-low', (3) 'Medium-high', and (4) 'High'. The proportions of individuals selecting each category were: $21.7,31.7,35.6$, and $11.0 \%$, from (1) to (4), respectively. Note that this question was introduced at the very end of the survey to avoid priming respondents about the occurrence of corruption before asking them about trust. Similarly, the interviewers did not mention at any moment that the survey was related to the issue of corruption.

\subsubsection{Sample}

The survey included individuals that were resident in the selected municipality and aged over 18, i.e. the voting age, in 2009. The sample used in our main estimation includes all individuals (assumed to be) exposed to the corruption scandal. This includes the individuals that were living in the municipality when news of the scandal broke and who were above the voting age at the time of the local election following the scandal. By selecting the sample in this way we eliminate around a thousand individual observations (i.e., we move from 8002 individuals to 6902) but we keep all the municipalities. We also checked to ensure that this does not affect the balance of individual covariates between the treated and control groups. The individuals (assumed to be) less exposed to corruption scandals (i.e., under the voting age in the elections following the scandals

\footnotetext{
${ }^{17}$ To check that this wording does not create confusion, we repeated the analysis using the answers to another survey question that refers specifically to the mayor: 'In the case of your city, do you think the mayor can be trusted?'. The correlation between the answers to both questions is very high, and the results of the analysis using the answer to this question (not presented here for the sake of brevity but available upon request) are very similar to those obtained when using the more general question.
} 
and/or taking up residence in the municipality after the scandal) are used later to perform a falsification test.

\subsection{Identification and estimation}

Our aim is to determine whether residents in municipalities that have experienced a corruption scandal before our survey report lower levels of trust (and higher perceptions of corruption) than residents in municipalities not exposed to a scandal. Our main methodological concern is the fact that neither corrupt practices nor the probability of uncovering them are randomly distributed in space. To address concerns about selection into the corruption status, we employ four different strategies (namely, matching, regional fixed effects, sensitivity analysis, and falsification tests), which are discussed in detail below. At the end of the section, we discuss whether selective attrition or sorting of individuals into treated and control units might constitute a problem.

\subsubsection{Matching}

The first empirical strategy is that of selection on observables. The survey used in obtaining our trust and corruption perceptions data was carried out on a matched sample of corrupt and non-corrupt municipalities, selected using propensity score matching. Below we briefly describe the design of that survey, the implementation of propensity score matching, and the estimation procedure.

Survey. Here there is a brief description of how we designed our survey Owing to data limitations, the selection of treated units was restricted to municipalities with more than 1,000 residents; ${ }^{18} 495$ of the 557 municipalities affected by corruption scandals are in that size category. Moreover, due to budget constraints, the survey was conducted with a subsample of these municipalities. In the end, a total of 160 municipalities in which corruption had been reported were selected as the treatment group and 131 very similar municipalities formed the control group. The number of controls is smaller as some of these municipalities are used as controls for more than one treated municipality (see the justification for this below). In each of these municipalities, between 20 and 50 residents older than 18 years at the time of the survey were interviewed, depending on population size (see also Box A.1 in the Appendix). ${ }^{19}$ These interviews were stratified according to

\footnotetext{
18 Spain has 8,114 municipalities, of which 3,252 have more than 1,000 inhabitants, those belonging to the control. These municipalities include $85 \%$ of the overall population.

${ }^{19}$ Non-EU immigrants were not included in the survey, since the vast majority of them cannot vote. EU nationals are included, survey because they are eligible to vote at local elections.
} 
age and gender. The selection of treated units ensured representativeness of the scandals by year and population size.

Propensity score matching. We selected the control municipalities using 'propensity score' matching. A Probit model was estimated, using as a dependent variable a dummy equal to one if a corruption scandal had been reported in the municipality (and zero otherwise) and as explanatory variables those factors deemed to have an influence both on corruption and on the level of trust in local politicians (see below). ${ }^{20}$ The 'propensity score' was then computed and control municipalities were matched to the treatment units based on their having a similar 'propensity score'. ${ }^{21}$ We followed the best practice for this type of design (Stuart and Rubin, 2007): we first matched the treated and control units using different methods and chose the one that guaranteed the best balance. The methods tested were 'nearest neighbour matching with replacement', 'one-to-one matching', 'radius matching' and 'kernel matching'. The method chosen to select the matched sample was 'nearest neighbour matching with replacement'. This method allows a given control unit to match more than one treatment unit, which increases the average quality of matching and reduces the bias. ${ }^{22}$

The municipal-level variables used in the estimation of the selection equation were: $\%$ Turnout (i.e., historical average of turnout at local elections), \% Right voters (historical average of right-wing voters), $\log$ (Population), \% Unemployed, Ethnic diversity, Income per capita, \% College, and \% Divorced. The information for these variables is drawn from sources dated as close as possible to the first year in the surge of corruption scandals in our database, so that they can be considered as pre-determined (see Table A.1 in the Appendix for the definition and sources of these variables). In line with Ho et al. (2007), we opt for a parsimonious specification in which all the variables are statistically significant and help predict the outcome (Table A.2 in the Appendix shows the estimated coefficients of the Probit). The use of this specification produced a good balance of covariates and good matches.

\footnotetext{
20 The Probit equation was estimated with information for all 495 corrupt municipalities with more than 1,000 inhabitants plus all the non-corrupt municipalities of the same size. The random selection of corrupt municipalities (and of their matched pairs) for inclusion in the survey was performed afterwards. We checked that both the original sample and the randomly selected sample satisfied the balancing property.

${ }^{21}$ Just eight municipalities in the original sample fell outside the common support and were not included in the survey. The municipalities randomly selected for the survey satisfy this property. 22 The matching is quite good, with $95 \%$ of the matches with an absolute propensity score distance lower than 0.01 and all the matches with a distance lower than 0.03 , which was the caliper finally used. Figure A.2 in the Appendix plots the propensity score distribution.
} 
The choice of variables was determined by a literature search focused on the determinants of corruption and trust, and by data availability. First, we use the historical turnout at the local elections as the main proxy for structural trust. Corruption is known to be more prevalent in places with low levels of social capital and/or low trust in government (Nannicini et al., 2013). We also know that turnout is a good proxy for social capital and trust in government, hence places in which turnout has historically been high are considered to show lower levels of corruption. Second, we control for voter ideology by including the proportion of right-wing voters. Several surveys show that the level of support for democracy in Spain is lower among right-wing voters (although support remains relatively high), mainly because the national right-wing parties were filled with high-ranking officials from Franco's regime. A number of studies also suggest that rightwing voters are more tolerant of corruption and that right-wing politicians have stronger connections with private firms (Solé-Ollé and Viladecans-Marsal, 2012 and 2013). Third, we control for the size of the municipality because some authors have documented that trust in government rises as the size of the polity falls (Rahn and Rudolph, 2005), while a prediction in the opposite direction has been made for political participation and accountability (Lassen and Serritzlew, 2011) and, hence, potentially for corruption. Fourth, there is also evidence that trust is negatively affected by belonging to a minority, living in a racially mixed community, having experienced a recent traumatic experience (e.g., divorce, unemployment), and being economically unsuccessful in terms of income or education (Alesina and La Ferrara, 2002). Some studies also suggest that corruption is more prevalent in polities with low levels of education, and that corruption is related to income, unemployment and ethnic diversity (Glaeser and Saks, 2006).

Using the aforementioned variables we are able to balance the covariates in the two subsamples. We performed several tests to determine whether or not a good matching was achieved. First, we performed a comparison of means between treated and control units in the unmatched and matched samples (see Rosenbaum and Rubin, 1985). The results of these tests are shown in Table A.4 in the Appendix. In the matched sample, none of the differences in means between the treated and the control group are statistically significant. Second, we also examined the percentage reduction in the standardized bias as a result of the matching procedure and found it to be substantial for all the variables that showed a statistically significant bias before the matching: \% Turnout (79\% fall), Ethnic diversity (86\% fall), log(Population), \% Graduates and \% Divorced (98\% fall each). Third, we also re-estimated the propensity score on the matched sample and compared the pseudo- $\mathrm{R}^{2}$ s before and after matching, which were 0.237 and 0.002 , respectively. LR 
tests of joint significance of the regressors before and after matching presented values of 624.25 and 2.32, with p-values of 0.000 and 0.941 . We also report this information for the other matching methods used (see Tables A.3 and A.5 in the Appendix). None of these other methods ('one-to-one', 'kernel' and 'radius' matching) out-performed the one chosen in terms of bias-reduction.

Finally, note that our sample is also balanced with regard to the individual-level variables obtained from the survey (see Table A.7 in the Appendix). The balance at the individual level is probably the result of the stratified nature of the survey regarding some demographics (age and gender). In any case, this property implies that, in practice, we are comparing the levels of trust of very similar individuals living in very similar municipalities. Note that this is an important property, since different types of individual might react in a different way to corruption scandals. If individual characteristics were not balanced between treated and control units, we should have implemented a doublematching procedure, both at the municipal and at the individual level (Keele and Zubizarreta, 2017).

Estimation. We follow the recommendation made by Ho et al. (2007) and estimate a parametric model with the data from our final matched sample. Other authors, such as Rubin (2001) and Crump et al. (2009), similarly recommend this procedure, suggesting that the propensity score should only be used for systematic sample selection as a precursor to regression estimation (or to more complex parametric methods). In most studies using matching techniques, the analysis performed to obtain the treatment effect is a simple difference in means (or the equivalent to a bivariate regression between the treatment indicator and the outcome, in the parametric case). However, it is well known that if the matching is not exact, this procedure can be improved by adjusting for covariates (Abadie and Imbens, 2011). There are several ways in which this adjustment can be performed in a non-parametric way (Abadie and Imbens, 2011; Rubin, 2001; Dehejia and Wahba, 1999), but for the parametric case an obvious approach is simply to run a multivariate regression with the matched sample and the covariates used in the estimation of the propensity score. Ho et al. (2007) recommend this procedure and suggest treating the predetermined covariates as fixed, meaning that standard errors and confidence intervals should be computed as in a normal regression framework. ${ }^{23}$

\footnotetext{
${ }^{23}$ In some types of matching, parametric analysis might require some adjustment. For instance, when using 'matching with replacement', weights must be used to ensure that the analysis reflects the actual observations (see Ho et al., 2007). We take this into account in our estimation.
} 
In our case, the multivariate regression has two additional advantages. First, it allows us to use the individual-level information extracted from the survey as additional covariates. ${ }^{24}$ The individual variables we use as additional controls are Income, Education, Age, Female, Divorced, Unemployed, Student, Retired, and Immigrant (see Table A.1 in the Appendix for their definition). Controlling for individual-level variables is standard in the empirical analysis of trust (Alesina and La Ferrara, 2002; Anderson and Tverdova, 2003; Chang and Chu, 2006). In doing so we also increase the precision of the estimation, although given the balance in these individual covariates, they should not have a marked impact on the results. Second, we can also include in the equation additional controls that were discarded from the final specification of the Probit used in the matching procedure or regional fixed effects (see below). Third, the use of a parametric framework allows us to choose the most appropriate estimation method. In our case, since our dependent variable is categorical, we use an Ordered Logit model.

\subsubsection{Fixed effects}

The second strategy we use to deal with omitted variables is the introduction of regional fixed effects in the equation. We believe that most of the potentially omitted determinants of corruption and trust (e.g., those related to cultural and historical influences or to areawide economic shocks) operate mainly at the regional scale and, thus, they might be correctly captured by provincial fixed effects. In all the equations, therefore, we include a set of provincial fixed effects. These fixed effects also help us to deal with another potential concern, related to the possibility that corruption scandals could be spatially clustered. We know, for instance, that the proportion of corrupt-ridden municipalities differs across regions. Failure to account for these spatial influences could bias the estimated effect of corruption on trust, as the response of trust to corruption may not be due to a reaction to a local scandal but the effect of the accumulation of scandals at the aggregate level and/or the effect of spatially correlated omitted influences. Having said that, we opted not to match at the regional level in order to ensure we found good matches for most of our corrupt units. We consider fixed effects to be a better option for dealing with this problem in our case.

\subsubsection{Sensitivity analysis}

A third strategy to help us rule out the possibility that the results are driven by omitted variables is the implementation of a sensitivity analysis, such as the one proposed by

\footnotetext{
${ }^{24}$ We deal with the multilevel structure of the dataset, with individuals belonging to different
} municipalities, by clustering standard errors at the municipality level. 
Imbens (2003) which explicitly models the degree of unobserved selection into the treatment. This method is based on the idea that the severity of the selection bias derived from the omission of a variable will be higher, the higher (at the same time) the correlations are between this variable and both the treatment and the outcome. To implement the analysis, we simulate a hypothetical omitted variable that could reduce our estimated effect by half, and compare the correlations with the treatment and outcome of this variable and, also, of the variables that we actually use in the matching. If none of these variables (or groups of variables) has the same level of correlation with the treatment and outcome as presented by the simulated variable, we conclude that the omission of variable as such is unlikely. ${ }^{25}$

\subsubsection{Falsification tests}

Our main falsification test relies on information on future treatments that should not have an effect on the outcome. More specifically, we rely on the fact that many more corruption scandals have been reported since our survey was conducted. Although we do not have a complete record of the scandals that broke out in the period 2010-2013, we know from the press that the phenomenon continued at a similar level of intensity. This suggests that it would be worthwhile conducting an additional search in MyNews to find additional news reports related to corruption in the 131 municipalities selected as controls using our matching procedure (and which, therefore, had not been exposed to any corruption scandals before we conducted the survey). These searches were performed during January 2014 and we found a total of 42 municipalities in which a scandal was reported during the period 2010-2013. ${ }^{26}$ Following the identification of this group, we compare their level of trust (or perception of corruption) with the level reported in municipalities that continued to be corruption-free.

Our second falsification test is based on the idea that for scandals to have an influence on trust and corruption perception, individuals have to be exposed to the scandal. Thus, individuals taking up residence in a municipality some years before the scandaland those that have been living in the community for a long time should be equally

25 Other sensitivity tests are based on the same intuition. See, for example, Becker and Caliendo (2007) or Nannicini (2007). Given our data limitation, we use the test proposed by Imbens (2003). 26 This might seem a high number at first glance. Note, however, that these municipalities were selected from the control group, and so they had a very high probability of being affected by a corruption scandal (in fact the mean propensity score for this group was 0.385 , while it was only 0.234 for municipalities exposed to scandals before the survey). As such, it seems quite natural that they should be the ones affected by these later corruption scandals. The fact that our Probit equation can predict the occurrence of future corruption scandals is further evidence that we are actually accounting for the relevant drivers of such scandals. 
affected by the corruption scandal, given that the two groups have been equally exposed to information about the corruption scandal. Note that as this group of recent arrivals is small, its trust levels probably do not matter much for the behavior of the local government, which means the findings for this group should be less affected by reverse causality. But, it would be problematic were we to find that this group is not affected at all by the scandal. The third falsification test is based on the idea that the effects on trust and corruption perceptions should be lower for individuals not directly exposed to the scandal (i.e., because they did not live in the town or because they were too young to vote) than they are for the rest of the citizens. ${ }^{27}$

\subsubsection{Selective attrition and sorting}

One additional concern is that following the scandal different types of individual move out of/into the treated and control municipalities. Imagine, for example, that more (less) highly educated individuals move out (in); since these individuals tend to report higher (lower) levels of trust in government, the impact of the corruption scandal on reported trust might also be greater than for the whole population. Likewise, if more (fewer) of these highly educated individuals were present in corrupt municipalities at the moment of the survey the estimated effects would be biased downwards (upwards). In order to deal with this concern, we provide evidence that the demographic composition of individuals moving into treated and control municipalities after a scandal is similar. We also discuss how large this sorting problem would need to be to substantially undermine our results.

\section{Results}

\subsection{Main results}

The main results of the estimation are presented in Table 1. The top panel presents the results for Trust in local politicians, while the bottom panel presents the results for Corruption perception. In each panel, the first five columns report the results using an Ordered Logit model, while the last three columns present simple OLS results collapsing the four categories (of either trust or corruption perceptions) into just two and using a

\footnotetext{
${ }^{27}$ We expect the effects on these individuals to be smaller than for the rest of the citizens but not necessarily zero. For instance, although these individuals were not directly exposed to the corruption scandal, they might have been exposed to higher corruption perceptions through socialization after growing up or after arriving in town. Likewise, if perception of corruption is not the only mediator of the effects of corruption on trust, their trust levels might be lower even if the perception of corruption has completely vanished before they grew up or before they arrived in town.
} 
high vs. low dummy (in columns (vi) and (vii)) with the individual data, or with the share of individuals reporting a high value (in column (viii)) and so aggregating the data at the municipality level.

\section{[Insert Table 1]}

The results suggest that the occurrence of a corruption scandal has a negative and statistically significant effect (at the $1 \%$ level) on trust in local politicians. This result holds whether or not we include provincial fixed effects in the equation, or control for historical turnout (a proxy of the previous level of trust in the municipality), for all the contextuallevel variables, and also for the individual characteristics. ${ }^{28}$ The conclusions are also the same when we use a simple OLS model, irrespective of whether we use individual or municipality data. ${ }^{29}$ This provides additional validation of the capacity of our matching procedure to balance the observable characteristics. The table also shows that corruption scandals have a statistically significant effect on the perception of corruption. Again, these results are robust to including different types of controls and to the estimation method.

Marginal effects. The fact that the effects of corruption scandals on trust in government are negative and statistically significant does not necessarily mean that these effects are quantitatively meaningful. One drawback of the Ordered Logit model is that the size of the estimated coefficient cannot be directly interpreted. The interpretation requires the computation of the marginal effects of a corruption scandal in each of the four categories of trust. In the top panel of Table 2 we present these marginal effects, computed as the difference in the predicted value of probability of choosing one of the trust categories as the corruption dummy changes from zero to one, while all other variables are held constant at their mean value.

\section{[Insert Table 2]}

Looking at the first row of Table 2, we see that when a corruption scandal is reported, an additional $4.7 \%$ of the whole population state that 'Local politicians can never be trusted' (category 1), and an additional 1.6\% state that 'Local politicians can almost never be trusted' (category 2). Conversely, after a corruption scandal the population

\footnotetext{
${ }^{28}$ Although contextual variables do have some influence on trust levels - historical turnout and population size being the most influential (full results, available upon request) - individual variables are more relevant - here, specifically, age, education, gender and immigration status. This is a typical finding in the trust literature (see, e.g., Alesina and La Ferrara, 2002).

${ }^{29}$ Clearly, the cut tests suggest that the most appropriate model is the Ordered Logit model, both in the case of trust and in the case of corruption perceptions. However, the fact that the main conclusions of the analysis also hold for alternative specifications is reassuring.
} 
stating that 'Local politicians can be trusted most of the time' (category 3) falls by 4\% and the population stating that 'Local politicians can always be trusted' (category 4) falls by $2.2 \%$. Overall, $6.2 \%$ of the population shifts from trusting to not trusting politicians as a result of a corruption scandal.

To appreciate the size of these numbers, they need to be put in perspective by considering the effect of corruption on the proportion of individuals in each category. Note for instance that in a corrupt-free municipality, around $10 \%$ of the individuals are grouped in category 4 ((b) in Table 2), while this proportion falls to around $8 \%$ in corruptridden municipalities $((b)+(a))$. This means that the number of individuals in this category falls by $20.8 \%$ after a case of corruption ((a)/(b)). The number of individuals in category 1 rises by a similar percentage (22\%) as a result of corruption, whereas the percentage changes in the number of individuals in categories 2 and 3 are not so great ( $+5 \%$ and $-11.1 \%$, respectively). If we combine the two high-trust and the two low-trust categories, we find that the number of individuals expressing trust in the government falls by $15 \%$ and that the number of individuals expressing a low level of trust in the government increases by $12.5 \%$. These effects seem to indicate that corruption scandals are quite capable of eroding levels of trust in local politicians among a significant percentage of the population.

Finally, note also from the bottom panel in Table 2 that the effects are qualitatively similar in the case of Corruption perception. The percentage of citizens shifting from low to high corruption perceptions is approximately the same as the percentage shifting from high to low trust categories (i.e., $7.5 \%$ vs. $6.2 \%$ ). These results appear to point to a link between corruption scandals, corruption perceptions and trust in local government: corruption scandals modify perceptions, and as a result individuals are less likely to trust the government. However, as discussed in the introduction, note that corruption scandals might trigger changes in other economic and political factors that can further erode future levels of trust, besides the effect operating through a higher perception of corruption.

\subsection{Validation of the results}

In this section we present the results of several checks performed to validate our results: a sensitivity analysis to assess the potential effects of omitting a relevant variable, several falsification tests performed with the same purpose, and some additional checks on the reliability of the matching methods used. 


\subsubsection{Sensitivity analysis}

Figure A.3 in the Appendix summarizes the results of the analysis performed following Imbens (2003). In Panel (a) we report the results for trust and in Panel (b) those for corruption perceptions. The downward sloping curve shown in the figure represents the combinations between the partial $\mathrm{R}^{2}$ of the simulated omitted variable $\mathrm{U}$ and either the level of trust or corruption perception that would be sufficient to reduce our treatment effect by half. The dots in the graph show the values of these two $\mathrm{R}^{2}$ for the different variables that we account for. Note that, in both graphs, only population size, historical turnout, and the provincial dummies seem to be substantially correlated at the same time both with the breakout of a corruption scandal and with trust or corruption perception. The remaining variables either have a very small influence on both variables or matter for trust or corruption, but not for the two of them at the same time.

None of our variables are located above the curve, which is the problematic area. The graphs show that to undermine our results substantially (i.e., by half), the ability of such an omitted variable to explain differences in trust levels should be more than twice that of all the contextual variables we account for, while its ability to explain the corruption status should be more than twice that of the provincial dummies. We believe both scenarios to be quite implausible.

\subsubsection{Falsification tests}

The first test performed compares the effect of corruption scandals on two groups of municipalities: those in which the scandal broke out before the survey (that is, the previous sample) and those in which the scandal broke out after the survey was carried out. There is a difficulty in performing this analysis: the newly corrupt municipalities are not necessarily comparable to the controls which were chosen to be as similar to the old corrupt municipalities as possible. To ensure that the treatment and control groups are comparable, we use the propensity score estimated earlier (see section 3.2) with the sample of 131 municipalities. We select matched pairs for each of the treated units using 'nearest neighbor matching with replacement' with a 0.03 caliper and dropping the observations that fall outside the common support (i.e., the procedure used to select our initial matched sample). We obtain a final sample of 75 municipalities, 38 in the treatment group and 37 in the control. ${ }^{30}$ Note that these two samples are identical in terms of

\footnotetext{
30 Our procedure guarantees that this sample is balanced (see Table A.6 in the Appendix and Table A.8 for balance between the contextual and individual variables, respectively).
} 
observables, meaning that if unobservables are unimportant we should not find any differences in levels of trust between them.

\section{[Insert Table 3]}

The first two columns in Table 3 present the results of this falsification test. Panel (a) presents the results for trust and Panel (b) for corruption perception. For the sake of comparability, column (i) reports the results already obtained: corruption scandals occurring before the survey have a negative (positive) and statistically significant effect on the level of trust in local politicians (on the perception of corruption). The results in column (ii) show that scandals breaking out after the survey have a very small and nonsignificant effect on both trust and on corruption perceptions. Note that independently of whether the scandal occurs before or after the survey, our matching procedure ensures that treated and controls are identical in terms of observables. This means that the estimated coefficient will pick up the genuine effects of the corruption scandal on trust plus the effect of any omitted variable that is correlated at the same time with corruption and with trust. The very small and non-significant effect of the coefficient of post-survey scandals (coupled with the large coefficient on the pre-survey scandals) suggests that the effect of these omitted variables is negligible.

Columns (iii) and (iv) of Table 3 present the results of our second falsification test, which compares the responses of individuals that recently moved into the municipality (column (iv)) with the responses of those that were already living there (column (iii)). ${ }^{31}$ In this case, we define recent movers as those that moved into the municipality less than five years before the scandal breakout, and people already living there as those that moved there more than five years before (and who might eventually live in the municipality for the whole of their lives). The control units are the same demographic groups in the municipalities as the controls for each treated municipality. The results are insensitive to this threshold. ${ }^{32}$ All the individuals exposed to corruption present a lower level of trust and higher corruption perception. The results of this test help us to rule out the possibility that the effect is due just to reverse causality. ${ }^{33}$

\footnotetext{
31 Both samples are balanced (see Table A.6 in the Appendix for balance between the contextual variables and Table A.8 for that between the individual variables).

32 Additional results using a ten-year cut-off or when defining recent movers as non-born in the municipality are nearly identical to those presented herein. Results with a smaller cut-off are similar in size but also more imprecise due to the smaller number of observations.

33 One possible concern is the difference in the size of the estimates for the two treated groups. The most plausible explanation for this difference is that the demographic composition of the two groups is different. We checked this and found that newcomers are younger, more educated and
} 
Column (v) in Table 3 presents the result for individuals who in theory were not exposed to the scandal. To implement this test, we examine the reaction of individuals exposed to the corruption scandal, defined as those that were both living in the municipality at the time of the scandal and who were also over the age of 18 at the time of the first local election immediately following the breakout. Individuals not exposed to the scandal are those that do not fulfil one of these two conditions: either they arrived after the scandal or they lived in the municipality but were under the voting age. This sample is also balanced. ${ }^{34}$ The implicit assumptions here are that information about a corruption case is acquired by being there when the scandal breaks out and that individuals that cannot vote at local elections do not have any incentives to be informed about politics. The results suggest that the effects of corruption on individuals (in theory) not exposed to the scandal are much smaller than they are for the rest of individuals and that they are not statistically significant at conventional levels. These results when compared with those in column (i) allow us to conclude that only individuals exposed to the scandal are substantively affected by scandals.

A shortcoming of these last two tests is that they are based on a smaller number of municipalities (for some treated and/or control units there are no individuals in these two groups). We show in the Appendix that treated and control groups are still quite similar in terms of observables. Another concern is the comparability of the results for the different treated groups, since they are demographically different (e.g., individuals under voting age and recent movers are younger than the rest of the respondents, both in the treated and control groups). We do not consider this to be a major problem in our case, since the falsification test is not based on comparing the size of the estimates but rather on finding a non-zero or a zero effect for some subgroups.

\subsubsection{Selective attrition and sorting}

We have performed some additional checks to ensure that sorting of specific types of individuals into treated and control municipalities after the scandal is not problematic. First, the percentages of individuals moving in after the scandal is very similar in both

richer. Such individuals might both report higher levels of trust in the government and react more to a scandal, thus explaining the larger effect. To determine whether this is the case we re-estimate the equation for the longstanding residents after re-weighting the individual observations of both treated and control municipalities to ensure a similar demographic composition of the two groups. The coefficients estimated for trust and corruption perceptions are now higher and more similar to those of the newcomers (full results are available upon request).

${ }^{34}$ See Table A.6 in the Appendix for balance between the contextual variables and Table A.8 for that between the individual variables. 
treated and corrupt municipalities (see Table A.9 in the Appendix). Second, the demographic characteristics of individuals moving in after the scandal are also identical in the two groups (see the same table). Finally, although we do not have information on individuals moving out, we know that recent movers represent a very small percentage of the population (i.e., around 7\%), which means that the differential impact of the scandal on the movers would have to be very large to have a meaningful impact on our estimates.

\subsubsection{Additional checks}

In addition to the above analyses, additional evidence for the reliability of our results is provided by the fact that the main results presented in Table 1 are robust to the inclusion in the equation of additional controls. The variables considered here were those discarded in the estimation of the Probit used in the matching procedure. Although none of these variables was statistically significant, some presented the expected sign and had zstatistics close to one. These variables can be grouped into three categories: (i) additional measures of turnout (i.e., change in turnout over the period 1987-1995, and average historical turnout measured at the provincial level), (ii) other plausible proxies of social capital (i.e., newspaper circulation or number of associations, both in per capita terms), and (iii) variables measuring corruption opportunities, related mainly to urban growth (i.e., population growth, and specialization in the tourism industry, proxied by the percentage of vacation homes). ${ }^{35}$

In Table A.10 in the Appendix we present the results obtained when including different sets of additional variables in the equation. If they were correctly excluded from the Probit, the results should not vary greatly. The three columns of the table replicate the results when including in the equation the variables that were discarded in the estimation of the Probit but which had z-statistics close to one (as mentioned above in section 3.2). The first column controls for other measures of turnout, the second for other plausible social capital proxies, and the third for variables that measure corruption opportunities. The results do not vary much in any of the three cases.

\subsection{Timing of the effects}

The second idea that the paper aims to explore is whether the effects of corruption scandals on trust in local politicians are long lasting or not. Note that while the survey was undertaken at the end of 2009, the corruption scandals span the years 2000 through to 2009. Scandals breaking out just prior to the survey might therefore have a very different

\footnotetext{
35 A number of other plausible confounders (e.g., past margin of victory of the local incumbent, number of terms in office, etc.) had no explanatory power equation and were not considered.
} 
effect on the levels of trust and the perception of corruption as reported by the respondents to the survey.

Estimation results. In order to investigate whether the initial impact of corruption scandals on trust and on perceptions of corruption fades over time or whether this effect is persistent, we re-estimate our model introducing an interaction with the dummy that identifies whether there has been a corruption scandal in the municipality and the distance in time between the year of the survey and the year of the scandal. ${ }^{36}$ The year of the scandal is defined as the year that concentrates the highest number of news stories about the case. One concern with this definition would be that media coverage of a scandal spreads across many years. We have inspected the data and find that this is not generally the case for most of the scandals. ${ }^{37}$ The results of this analysis are reported in Table 4 . In Panel (a) we report the results for Trust in local politicians and in Panel (b) the results for Corruption perceptions. The first three columns report the results from the estimation of an Ordered Logit and the last three for the OLS estimation. For purposes of comparison, the first column for each method presents the results without interaction. The second column adds the interaction with the distance to the scandal. Both columns include all sets of control variables: provincial dummies, historical turnout, contextual variables and individual variables. The third column adds some additional variables that control for differences in the seriousness of the corruption scandal and/or the expected impact of the case. $^{38}$

The coefficient on the interaction between the corruption dummy and the distance variable is not statistically significant in the case of trust, suggesting that the effect of corruption scandals on trust does not depend much on the distance to the breakout. In contrast, the interaction coefficient is negative and statistically significant in the case of corruption perception. This indicates that the effect of corruption scandals on perceptions tend to fade with the passage of time.

[Insert Table 4]

\footnotetext{
36 This variable has been demeaned, so the coefficient on the corruption dummy will indicate the effect measured at the average distance, which is four years.

${ }^{37}$ Around $80 \%$ of the scandals have all the news stories concentrated in a single year. Most of the remaining scandals generate some news stories in the year following the scandal but generally in a year before the next local elections. There are just a few municipalities with more than one maximum, but the results are robust to the treatment of these cases.

38 For instance, we include a dummy identifying election years (i.e., one for 2003 and 2007) and a dummy identifying whether press coverage has been particularly high (i.e., equal to one if the number of news stories is higher than might be expected for a municipality of that size).
} 
In order to better gauge their magnitude, in Figure 1 we plot the marginal effects derived from the estimates in Table 4. In order to facilitate interpretation, we present the marginal effects derived from the OLS results, but the results originating from the Ordered Logit (for the four categories) present a very similar picture. Likewise, to facilitate the comparison between the dynamic effects on trust and those on corruption perceptions, we report the marginal effects in terms of increases in perceptions and decreases in trust (thus reversing the signs of the coefficients). The graph shows that the marginal effect (the percentage share of the population shifting to high perceptions or to low levels of trust) is a flat line in the case of trust and a negative slope in the case of corruption perceptions. The marginal effect on corruption perception at year zero is around $10 \%$, while this value drops to around $5.5 \%$ by the end of the period, meaning that around $50 \%$ of the impact of corruption on corruption perception has disappeared after a decade. In the case of trust, the marginal effect at year zero is around $7 \%$, while it remains around $6.5 \%$ by the end of the period, suggesting a more persistent effect. The reasons for this difference are investigated in the next section.

[Insert Figure 1]

\subsection{Mechanisms}

To assess the role of corruption perceptions vis-à-vis other mechanisms, we perform a mediation analysis. We first discuss the specification and the assumptions needed for the identification. We then select the mediators used in the analysis. Finally, we present the results. For the sake of simplicity, we assume that the relationships between corruption scandals, trust and the mediators are all linear. We have already shown in Table 1 that the main results hold when we estimate an OLS equation using a two-category variable to measure trust or corruption perception, so we use this specification here.

Specification. Following common practice (see Imai et al., 2010, Keele et al., 2015), we specify the following two-equation linear model:

$$
\begin{gathered}
M_{i}=\alpha+\beta C_{i}+\gamma X_{i}+\epsilon_{i} \\
T_{i}=\delta+\theta C_{i}+\mu M_{i}+\Omega X_{i}+\varepsilon_{i}
\end{gathered}
$$

where $T_{i}$ is trust and $C_{i}$ is the dummy with a value of 1 if there has been a corruption scandal. The term $M_{i}$ denotes each of the potential 'mediators' of the effect of corruption on trust. The control variables are denoted by $X_{i}$ and include all the controls used up to now plus lagged values of the mediators (measured before the start of the period of analysis). The terms $\epsilon_{i}$ and $\varepsilon_{i}$ are error terms. The 'average causal mediation effect' for any 
of the mediators (or ACME) is $\hat{\beta} \hat{\mu}$ and $\hat{\theta}$ is the so-called 'direct effect', which is the effect that cannot be attributed to a specific mediator.

Substituting (1) into (2) we obtain:

$$
T_{i}=\pi+\vartheta C_{i}+\eta X_{i}+v_{i}
$$

This equation provides the 'total effect' of corruption scandals on trust. The total effect is $\hat{\vartheta}$ and the share of the total effect explained by each mediator is $\hat{\beta} \hat{\mu} / \hat{\vartheta}$.

Imai et al. (2010) show that the ACME is non-parametrically identified if the 'sequential ignorability' assumption is satisfied. This assumption holds if, first, the treatment (Corruption) is assumed to be ignorable given the pre-treatment covariates, and second, the mediator variables are assumed to be ignorable given the observed value of the treatment as well as the pretreatment covariates. The identification strategy of our main analysis relies on the first assumption, so there is nothing new here. The second assumption is more demanding, and would be violated if, for example, we were omitting an important mediator that is also correlated with one of the mediators we are interested in. To deal with this threat we do two things. First, we introduce several mediators at the same time, which allows us to show that the mediation effect attributed to one mediator (e.g., Corruption perception) does not change when we include the other mediators in the analysis. Second, we perform a sensitivity analysis, as proposed by Imai et al. (2010), which is based on the idea of studying how much correlated $\epsilon_{i}$ and $\varepsilon_{i}$ should be for a hypothetical omitted variable to be able to undermine the effect of a given mediator.

To study the role of each of the mediators over time, we add Time elapsed since the scandal (denoted as $\tau_{i}$ ) as a 'moderator' variable to equations (1) and (2):

$$
\begin{gathered}
M_{i}=\alpha^{\prime}+\beta^{\prime} C_{i}+\beta^{\prime \prime} C_{i} * \tau_{i}+\gamma^{\prime} X_{i}+u_{i} \\
T_{i}=\delta^{\prime}+\theta^{\prime} C_{i}+\theta^{\prime \prime} C_{i} * \tau_{i}+\mu^{\prime} M_{i}+\rho^{\prime} X_{i}+v_{i}
\end{gathered}
$$

Substituting (1') into (2') we obtain:

$$
T_{i}=\pi^{\prime}+\vartheta^{\prime} C_{i}+\vartheta^{\prime \prime} C_{i} * \tau_{i}+\eta^{\prime} X_{i}+\varsigma_{i}
$$

which shows that the 'total effect' also depends on the time elapsed since the scandal. Note that now the ACME depends on Time since scandal: $\operatorname{ACME}\left(\tau_{i}\right)=\left(\hat{\beta}^{\prime}+\hat{\beta}^{\prime \prime} * \tau_{i}\right) * \hat{\mu}$.

Mediators. We select our mediators from among a wider set of variables. The variables considered have been selected in line with theory (see section two) and data availability. Besides Corruption perception, we consider variables that capture the potential side effects of corruption scandals, such as, fragmentation of government, fiscal stress, and 
economic development (see Figure 2 for an illustration of the causal relationship). The specific variables finally selected as mediators are those shown to be affected by corruption scandals; however, when there are several variables capturing the same mechanism, we select the one that seems to be most obviously affected by the scandal.

[Insert Figure 2 and Table 5]

Table 5 shows the effect of corruption on all the variables considered as potential mediators. All equations use the same controls as those used in Table 4 plus the lagged values of all potential mediators measured at the beginning of our period of analysis. Panel (a) reports the average impact of a corruption scandal on each of the side effects, while Panel (b) explores the effect of the time since the break out of the scandal. Column (i) just corroborates one of the results of our main analysis: namely, that corruption increases the perception of corruption.

Columns (ii) and (iii) in Table 5 report the effects of corruption on two indicators of fragmentation that we have been able to compute for our municipalities: whether the mayor has a Majority of seats in the city council and a Herfindahl-Hirschman index of fragmentation of seats among the parties represented in the council (HH index, hereafter). This index moves from one (low fragmentation) to zero (high fragmentation). These indicators are measured at the end of our period and, as before, we control for their values at the beginning. The results inform us that after a corruption scandal the probability of having a Majority government falls by nearly $20 \%$ and the HHI falls by 0.021 . These are considerable probabilities if we take into account that the s.d. of these variables is $49 \%$ and 0.083 , respectively. Moreover, note that the impact of corruption on the two variables increases with the time elapsed since the scandal. The drop in probability of having a Majority government is $16 \%$ on impact and $23 \%$ at the end of the period, while the drop in the HHI goes from -0.015 to -0.032 . For our mediation analysis, we use the HHI, but the results are quite similar if we use the Majority dummy.

Columns (iv) to (ix) in Table 5 show the effects of corruption scandals on different budget items, measured around the time of the survey (i.e., 2009). The spending, taxes, and grants variables are measured per capita and in logs, so the coefficient can be interpreted as the \% increase in the item. The Deficit is equal to $\log$ (spending) minus $\log$ (taxes + grants); the average of this variable is close to one, so the coefficient can also be approximately interpreted as a \% increase. The results reported in column (iv) of Panel (a) show that, after a scandal, Capital grants (which also include development revenues) fall by an average of $9 \%$. Taxes increase by an average of $12 \%$ (see column v) and Deficits 
rise by $4 \%$ (see column vi). Column (vii) shows that current grants, on average, are not affected, which is expected since these are mostly formula grants. Local governments do not respond to corruption by adjusting their spending down (see columns viii and ix). The results in Panel (b) suggest that the reduction in Capital transfers is large and remains so over time (e.g., they fall by $14 \%$ just after the scandal and are still $9 \%$ lower ten years later). The impact on Deficits seems to attenuate over time, although the coefficient of the interaction term is not statistically significant. The behavior of taxes is just the opposite: tax increases are smaller at the beginning (around 11\%) but higher at the end (16\%). This time profile suggests that the impact of the cut in capital transfers is first absorbed by increasing the deficit and afterwards by tax increases. Taxes and Deficit are the two variables from this group that are used in the mediation analysis, the reason being that these are the variables that might be perceived by voters as indicative of a poor outcome, and which could potentially harm trust.

The last two columns in Table 5 report the effects of corruption scandals on two indicators of economic performance: the unemployment rate and the population growth rate. Again, both indicators are measured at the end of the period (year 2009). Although the results suggest that corruption helps reduce the unemployment rate and fosters population growth, the effects are not statistically significant at conventional levels. For this reason, we do not consider these variables in the mediation analysis. ${ }^{39}$

Main results. Columns (i) to (v) in Table 6 present the results of the estimation of equations (2) and (2'). Column (vi) reports the estimation of equations (3) and (3'). ${ }^{40}$ The results suggest that Corruption perception has a strong effect on Trust; moving from low to high corruption perception decreases the probability of having a high level of trust by approximately $30 \%$, and an increase of one s.d. in this variable generates a fall in trust of around $14 \%$. The effect of fragmentation is also notable: an increase of one s.d. in the HHI leads to an increase in trust of about $6 \%$. High taxes also harm trust in government; an increase of one s.d. in this variable causes trust to fall by $10 \%$. The deficit level does not have a statistically significant effect on trust.

\footnotetext{
${ }^{39}$ However, the inclusion of these variables would not affect the results. In results available upon request we show that unemployment/population growth reduce trust in government but that the mediation power of these variables is very low (due to the fact that they do not respond much to corruption). Their inclusion in the analysis does not affect the mediation power of the other variables considered.

40 The coefficients of equations (1) and (1'), which are also needed for the computation of the 'mediation effects', are taken from Table 5.
} 


\section{[Insert Table 6]}

As can be seen in Table 7, all the mediators when considered together are able to explain $62.3 \%$ of the effect of corruption on trust. The most important mediator seems to be Corruption perception, with a share in the total 'mediating' effect equal to $31.9 \%$ (that is, $51 \%$ of the 'mediated' effect). The mediator that follows in quantitative importance is the HHI, with a share equal to $16.5 \%$ (or $26 \%$ of the 'mediated' effect). Taxes also play a substantial role, with a share equal to $11.8 \%$ (or $18.9 \%$ of the 'mediated' effect). The effect of the deficit is much smaller (around 2\%); recall that while being quite strongly affected by the corruption scandal, the deficit does not have a clear impact on trust.

\section{[Insert Table 7]}

These results are quite robust. First, the mediation power of each variable does not change greatly when we include all the mediators at the same time. Second, following Imai et al. (2010), we show that the ACME is not very sensitive to the omission of variables that are correlated with the outcome and with the mediator at the same time. The results are reported in Figure A.4 in the Appendix. Note that under the 'sequential ignorability' assumption, the parameter $\rho \equiv \operatorname{Corr}\left(\epsilon_{i}, \varepsilon_{\mathrm{i}}\right)$ is zero. The analysis performed shows that the results for Corruption perception (the main mediator) are maintained unless there is an omitted variable that has a positive (negative) effect on trust and a negative (positive) effect on corruption perception generating a value of $\rho<-0.32$. This implies that our results are plausible even for significant departures from the ignorability assumption. This is also the case for the estimated mediated effect of fragmentation. However, in the case of taxes, the ACME is more sensitive to variations in $\rho$, suggesting that this specific result might be less reliable.

Imai et al. (2010) also show that the sensitivity parameter $\rho$ can be expressed as the product of the unexplained variance, for the outcome and the mediator, which is explained by an unobserved pre-treatment confounder. That is, $\rho=\operatorname{sign}(\lambda 1 \lambda 2) R_{Y}^{2 *} R_{M}^{2 *}$, where $R_{Y}^{2 *}$ and $R_{M}^{2}$ are the partial $\mathrm{R}^{2}$ of this potential confounder on the outcome and the mediator regressions and $\operatorname{sign}(\lambda 1 \lambda 2)$ is the sign of the potential bias that this potential confounder would generate. We can use this expression to determine the effect on the ACME of an omitted variable that has the same explanatory capacity as that of all the controls included in our regressions. The results show that Corruption perception and the HHI explain 36 and $15.4 \%$ of the effect of corruption on trust, respectively. These values do not differ greatly from those reported in Table 6 . The percentage effect mediated by 
Taxes would fall to 7\%, a much smaller percentage than the one reported above, again suggesting that this effect is less robust. ${ }^{41}$

The last column of Table 7 presents the range of values of the ACME as a function of Time elapsed since the scandal. Note first that the share mediated by Corruption perception falls abruptly with the passage of time: from $43.8 \%$ on impact to $17.6 \%$ after a decade. This contrasts with the cases of the HHI and Taxes, whose effects actually become much more intense with the passage of time. The share 'mediated' by the HHI grows from 12.1 to $26.5 \%$ and the share 'mediated' by Taxes grows from 6.7 to $15.7 \%$. These results suggest that the reason why the effects of scandals persist over time (recall Figure 1) is the fact that the scandal triggers some economic and political side effects, whose impact is magnified over time.

\section{[Insert Figure 3]}

Figure 3 depicts the marginal effects again of corruption scandals on trust (the sign of the coefficients is reversed). This time we decompose the effect to include just that due to these two mediators (i.e., fragmentation and fiscal stress) and the effect that the two do not explain. The graph clearly shows that the effect of these 'mediators' grows over time and that the effect not explained by them fades over time. In fact, if we compute the percentage share of the effect of corruption scandals on trust remaining after a decade using this adjusted measure of trust, we obtain a number that is very similar to the one obtained for the case of corruption perception: $62 \%$ vs. $55 \%$, respectively. Three main conclusions can be drawn from this analysis. First, Corruption perception seems to be an important 'mediator' of the effect of Corruption on Trust in government. Second, the increase in the perception of corruption after a scandal is gradually weakened over time, although Corruption perception is still considerably high one decade after the scandal. This effect translates into a reduction in the level of trust in government that also reverts back to pre-scandal levels over time. Third, this reversal is however not directly observed in the data because the scandal also generates other economic and political side effects

\footnotetext{
${ }^{41}$ For Trust, residual variation goes from 0.56 to 0.54 . For Corruption perception, residual variation goes from 0.99 to 0.97 . Assuming a positive bias, then $\rho=0.0008=(1-0.54 / 0.56)(1-0.97 / 0.94)$. For this value of $\rho$, Corruption perception would explain $36 \%$ of the effect of corruption on trust. For the $H H$ Index the residual variation goes from 0.97 to 0.36 ; assuming a negative bias, $\rho=-0.020=(1$ $0.54 / 0.56)(1-0.39 / 0.97)$. For this value of $\rho$, the mediated effect of the HH index would be $15.4 \%$. For Taxes residual variation goes from 0.66 to 0.34 . If we assume a positive bias, $\rho=0.022=(1-$ $0.54 / 0.56)(1-0.34 / 0.66)$; for this value taxes would explain a $7 \%$ of the effect of corruption on trust.
} 
that harm the level of trust in the local government and which become more intense over time.

\section{Conclusions}

Local corruption scandals can have a highly detrimental effect on the level of trust shown by citizens in local politicians. On average, we find that around 6\% of citizens shift from occupying high-trust to low-trust categories following a corruption scandal. While this proportion might not seem very high at first glance, it is considerable if compared with the actual number of people already classified in the low-trust categories. The number also represents a larger proportion than the percentage share of votes lost by corrupt incumbents (see, e.g., Peters and Welch, 1980) and, more specifically, by local incumbents in Spain (see Barberá et al., 2013, and Costas et al., 2012).

Our results also show that the effects of corruption scandals on trust are quite persistent. After a decade, the level of trust has not yet reverted to its pre-scandal level. We show that this is compatible with the fact that while the perception of corruption tends to fade over time, it is still substantial after a decade. We also show that the persistence in the effect on trust can be partly explained by other side effects that a scandal might provoke. For example, it seems that government fragmentation increases after a scandal and that this effect grows over time. Government fragmentation erodes trust in local government, probably because citizens dislike political struggles and policy gridlock. We also show that public finances tend to deteriorate after a scandal, due to cuts in grants and the failure to adjust expenditure, which over time results in tax hikes.

These results add further pessimism to the evaluation of the effects of scandals on trust in government. Although the negative impact a scandal has on citizen evaluations of government honesty may fade over time, the impact on the everyday operations of political life might be sufficiently disruptive to adversely affect citizen attitudes towards government over a longer time span.

\section{Acknowledgements}

The paper benefited from comments received from the Editor, two anonymous referees, the participants at the CESifo Conference on Public Economics, the European Public Choice Conference, the Midwest Political Science Conference, and at a seminar at the University of Heidelberg. We acknowledge the research assistance provided by Marta 
Curto-Grau and the work of Oriol Molas at Treball de Camp, who helped us in designing the survey. A previous version of this paper circulated with the title "Does corruption erode trust in government. Evidence from recent surge of local scandals in Spain." This research has received funding from projects EC02015-68311-R (Ministerio de Educación y Ciencia) and 2014SGR420 (Generalitat de Catalunya) 


\section{References}

Abadie, A. and Imbens, G. (2011): "Bias corrected matching estimators for average treatment effects," Journal of Business and Economic Statistics 29(1), 1-11.

Alesina, A. and La Ferrara, E. (2002): “Who trusts others?," Journal of Public Economics 85, 207-234.

Anderson, Ch. and Tverdova, Y. (2003): "Corruption, political allegiances, and attitudes towards government in contemporary democracies," American Journal of Political Science 47(1), 91-109.

Anduiza, E., Gallego, A., and Muñoz, J. (2013): “Turning a blind eye: experimental evidence of partisan bias in attitudes towards corruption," Comparative Political Studies 46(12), 1664-1692.

Barberá, P., Fernández-Vázquez, P. and Rivero, G. (2013): "The electoral consequences of corruption scandals in Spain," Crime, Law \& Social Change 60(6) 515-534.

Becker S. and Caliendo M. (2007): "Sensitivity analysis for average treatment effects", The Stata Journal 7(1), 71-83.

Blattman, C. (2009): "From violence to voting: war and political participation in Uganda", American Political Science Review 103(2), 231-247.

Bowler, S. and Karp, J.A. (2004): "Politicians, scandals, and trust in government," Political Behavior 26(3), 271-287.

Brollo, F. (2013): "Why Do Voters Punish Corrupt Politicians? Evidence from the Brazilian Anti-Corruption Program", mimeo, University of Warwick, https:// www2.warwick.ac.uk/fac/soc/economics/staff/fbrollo/whoispunishing_online.pdf

Bruter, M. (2009): "Time bomb? The dynamic effect of news and symbols on the political identity of European citizens," Comparative Political Studies 42(12), 1498-1536.

Cassar, A., Grosjean, P. and Whitt, S. (2013): "Legacies of violence: trust and market development", Journal of Economic Growth 18(3), 285-318.

Chang, E. and Chu, Y. (2006): "Corruption and trust: Exceptionalism in Asian democracies?," Journal of Politics 68(2), 259-271.

Chang, E., Golden, M., Hill, S., (2010): "Legislative malfeasance and political accountability", World Politics 62(2), 177-220.

Costas, E., Solé-Ollé, A., and Sorribas-Navarro, P. (2012): “Corruption, voter information, and accountability," European Journal of Political Economy 28(4), 469-484.

Crump, R.K., Hotz, V.J., Imbens, G.W. and Mitnik, O.A. (2009): “Dealing with limited overlap in estimation of average treatment effects," Biometrika 96(1), 187-199.

Dehejia, R.H. and Wahba, S. (1999): "Causal effects in non-experimental studies: reevaluating the evaluation of a training program," Journal of the American Statistical Associtation 94(448), 1053-1062.

Dimock, M. A. and Jacobson, G. C. (1995): “Checks and choices. The House bank scandal's impact on voters in 1992," Journal of Politics 57, 1143-59.

Eisensee, Th. and Stromber, D. (2007): "News Floods, News Droughts, and U.S. Disaster Relief," Quarterly Journal of Economics, 122(2).

Elenbaas, M. And De Vreese, C. H. (2008): "The effects of strategic news on political cynicism and vote choice among young voters," Journal of Communication 58(3), 550-567.

Fernández-Vázquez, P., Barberá, P. and Rivero, G. (2015): "Rooting out corruption or rooting for corruption?," Political Science: Research and Methods 4(2), 379-397. 
Fundación Alternativas (2007): Urbanismo y democracia. Alternativas para evitar la corrupción, Madrid. . www.falternativas.org.

Fundación Alternativas (2010): Democracy in Spain 2010. The erosion of confidence and well-being. Against citizens' disaffection, Madrid. www.falternativas.org.

Garfias, F. and Timmons, J. (2015): "Revealed Corruption, taxation and fiscal accountability: evidence from Brazil," World Development 70, 13-27.

Glaeser, E.L. and Saks, R.E. (2006): "Corruption In America," Journal of Public Economics 90(6-7), 1053-1072.

Heckman, J. and Hotz, J. (1989): "Choosing among alternative non-experimental methods for estimating the impacts of social programs: the case of manpower training," Journal of the American Statistical Association 84(408), 862-874.

Hetherington, M. (1998): "The political relevance of political trust," American Political Science Review 92(4), 791-808.

Hetherington, M. and Rudolph, T.J. (2008): "Priming, performance, and the dynamics of political trust," Journal of Politics 70(2), 498-512.

Ho, D., Imai, K., King, G., and Stuart, E. (2007): "Matching as nonparametric pre-processing for reducing model dependence in parametric causal inference," Political Analysis 15, 199-236.

Imai, K., Keele, L. and Yamamoto, T. (2010): "Identification, Inference and Sensitivity Analysis for Causal Mediation Effects", Statistical Science 25(1), 51-71.

Imbens, G. (2003): "Sensitivity to Exogeneity Assumptions in Program Evaluation", Recent Advances in Econometric Methodology 93(2), 126-

Imbens, G. and Wooldridge, J. (2009):"Recent developments in the econometrics of program evaluation," Journal of Economic Literature 47, 5-86.

Jiménez, F. and Caínzos, M. (2003). "Political corruption in Spain. Perceptions and problems," in M. Bull and J. Newell (eds.): Corruption in contemporary politics. London. Palgrave Press.

Kaplan, E. and Mukand, S. (2014): "The Persistence of Political Partisanship: Evidence from 9/11", mimeo, http://econweb.umd.edu/ kaplan/ideologypersistence1115.pdf

Keele, L. and Zubizarreta, J. (2017): "Optimal multilevel matching in clustered observational studies: A case study of the School Voucher System in Chile." Journal of the American Statistical Society, 112(518), 547-560.

Keele, L..., Yamamoto, T. and Tingley, D. (2015). "Identifying Mechanisms behind Policy Interventions via Causal Mediation Analysis." Journal of Policy Analysis and Management 34(4), 937-963.

Kleinnijenhuis, J., van Hoof, A-M.J. and Oegema, D. (2006): "Negative news and the sleeper effect of distrust," International Journal of Press/Politics 11(2), 86-104.

Kumlin, S. and Esaiasson, P. (2012): "Scandal fatigue? Scandal elections and satisfaction with Democracy in Western Europe, 1977-2007," British Journal of Political Science 42(2) 263-282.

Lassen, D.D. and Serritzlew, S. (2011): "Jurisdiction size and local democracy: evidence on internal political efficacy from large-scale municipal reform," American Political Science Review 105, 238-58.

Mian, A., Sufi, A. and Trebbi, F. (2014): "Resolving debt overhang: Political constraints in the aftermath of financial crises," American Economic Journal: Macroeconomics 6(2), $1-28$. 
Mishler, W. and Rose, R. (1997): "Trust, distrust and skepticism: popular evaluations of civil and political institutions in Post-Communist societies," Journal of Politics 59(2), 418-51.

Morris, S.D. and Klesner, J.L. (2010): "Corruption and trust: theoretical considerations and evidence from Mexico," Comparative Political Studies 43/10, 1258-1285.

Nannicini, T. (2007): "Simulation-based sensitivity analysis for matching estimators." The Stata Journal 7(3), 334-350.

Nannicini, T., Stella, A., Tabellini, G. and Troiano, U. (2013): "Social capital and political accountability," American Economic Journal: Economic Policy 5, 222-250.

Peters, J. G., Welch, S., (1980): "The effects of charges of corruption on voting behavior in Congressional elections", American Political Science Review 74, 697- 08.

Rahn, W. and Rudolph, T. (2005): "A tale of trust in American cities," Public Opinion Quarterly 69(4), 530-556.

Riera, P., Munt, I. and Keyes, J. (1991): "The practice of land use planning in Spain," Planning Practice and Research 6 (2), 11-18.

Rosenbaum, P.R. and Rubin, D.B. (1985): “Constructing a control group using multivariate matched sampling that incorporates the propensity score," The American Statistician 39(1), 33-38.

Rothstein, J. (2010): "Teacher quality in educational production: tracking, decay, and student achievement," Quarterly Journal of Economics 125(1), 175-214.

Rubin, D.B. (2001): "Using propensity scores to help design observational studies: application to Tobacco Litigation," Health Services \& Outcomes Research Methodology 2, 169-188.

Seligson, M.A. (2002): "The impact of corruption on regime legitimacy: a comparative study of four Latin American Countries," Journal of Politics 64(2), 408-433.

Solé-Ollé, A. and Viladecans-Marsal, E. (2012): "Lobbying, political competition and local land supply: recent evidence from Spain," Journal of Public Economics 96, 10-19.

Solé-Ollé, A. and Viladecans-Marsal, E. (2013): "Do political parties matter for land use policies?," Journal of Urban Economics 78, 42-56.

Stuart, E.A. and Rubin, D.B. (2007): "Best practices in quasi-experimental designs: Matching methods for causal inference," in J. Osborne (Ed.): in Best Practices in Quantitative Social Science, Chapter 11, pp. 155-176. Thousand Oaks, CA: Sage Publications.

Welch, S. and Hibbing, J., (1997): "The effect of charges of corruption on voting behavior in congressional elections, 1982-90," Journal of Politics 59, 226-239. 
Tables and figures:

Table 1: Effects of corruption scandals on Trust in local politicians

\begin{tabular}{|c|c|c|c|c|c|c|c|c|}
\hline & \multicolumn{5}{|c|}{ Ordered Logit } & \multicolumn{3}{|c|}{ OLS } \\
\hline & (i) & (ii) & (iii) & (iv) & (v) & $\begin{array}{l}\text { High v. } \\
\text { Low } \\
\text { (vi) }\end{array}$ & $\begin{array}{l}\text { High v. } \\
\text { Low } \\
\text { (vii) }\end{array}$ & $\begin{array}{l}\text { Share } \\
\text { High } \\
\text { (viii) }\end{array}$ \\
\hline \multicolumn{9}{|c|}{ (a) Trust } \\
\hline Corruption & $\begin{array}{c}-0.260^{* * *} \\
(0.071)\end{array}$ & $\begin{array}{c}-0.337^{* * *} \\
(0.081)\end{array}$ & $\begin{array}{c}-0.326^{* * *} \\
(0.082)\end{array}$ & $\begin{array}{c}-0.261^{* * *} \\
(0.080)\end{array}$ & $\begin{array}{c}-0.266^{* * *} \\
(0.080)\end{array}$ & $\begin{array}{l}-0.071^{* * *} \\
(0.019)\end{array}$ & $\begin{array}{c}-0.065^{* * *} \\
(0.020)\end{array}$ & $\begin{array}{l}-0.049^{* *} \\
(0.023)\end{array}$ \\
\hline $\begin{array}{l}\text { F-test. } \\
\text { Contextual var. }=0\end{array}$ & $--\cdot--$ & $-\cdot--$ & $-\cdot--$ & $\begin{array}{c}22.10 \\
{[0.002]}\end{array}$ & $\begin{array}{c}28.35 \\
{[0.008]}\end{array}$ & $--\cdot--$ & $\begin{array}{c}4.01 \\
{[0.000]}\end{array}$ & $\begin{array}{c}2.51 \\
{[0.016]}\end{array}$ \\
\hline $\begin{array}{l}\text { F-test. } \\
\text { Individual var. }=0\end{array}$ &.---- & $--\cdot--$ & $--\cdot-$ & $--\cdot-$ & $\begin{array}{l}125.10 \\
{[0.000]}\end{array}$ & $--\cdot--$ & $\begin{array}{c}13.18 \\
{[0.000]}\end{array}$ & $--\cdot-$ \\
\hline Cut test: $\mathrm{T} 1=\mathrm{T} 2$ & $\begin{array}{c}1251.24 \\
{[0.000]}\end{array}$ & $\begin{array}{l}1271.76 \\
{[0.000]}\end{array}$ & $\begin{array}{l}1268.97 \\
{[0.000]}\end{array}$ & $\begin{array}{c}1295.62 \\
{[0.000]}\end{array}$ & $\begin{array}{c}1295.93 \\
{[0.000]}\end{array}$ & $--\cdot--$ & $--\cdot--$ & --.-- \\
\hline Cut test: $\mathrm{T} 2=\mathrm{T} 3$ & $\begin{array}{c}3156.15 \\
{[0.000]}\end{array}$ & $\begin{array}{c}2982.82 \\
{[0.000]}\end{array}$ & $\begin{array}{c}2974.37 \\
{[0.000]}\end{array}$ & $\begin{array}{c}2908.65 \\
{[0.000]}\end{array}$ & $\begin{array}{l}2979.67 \\
{[0.000]}\end{array}$ &.---- & $--\cdot-$ &.---- \\
\hline \multicolumn{9}{|c|}{ (b) Corruption perception } \\
\hline Corruption & $\begin{array}{l}0.349^{* * *} \\
(0.097)\end{array}$ & $\begin{array}{l}0.437^{* * *} \\
(0.096)\end{array}$ & $\begin{array}{l}0.409^{* * *} \\
(0.095)\end{array}$ & $\begin{array}{l}0.321^{* * *} \\
(0.100)\end{array}$ & $\begin{array}{l}0.325^{* * *} \\
(0.099)\end{array}$ & $\begin{array}{l}0.086^{* * *} \\
(0.025)\end{array}$ & $\begin{array}{l}0.067^{* *} \\
(0.024)\end{array}$ & $\begin{array}{l}0.050^{* *} \\
(0.025)\end{array}$ \\
\hline $\begin{array}{l}\text { F-test. } \\
\text { Contextual var. }=0\end{array}$ &.---- & $-\cdot--$ & $-\cdot--$ & $\begin{array}{c}25.09 \\
{[0.000]}\end{array}$ & $\begin{array}{c}28.82 \\
{[0.000]}\end{array}$ &.---- & $\begin{array}{c}3.24 \\
{[0.002]}\end{array}$ & $\begin{array}{c}1.92 \\
{[0.065]}\end{array}$ \\
\hline $\begin{array}{l}\text { F-test. } \\
\text { Individual var. }=0\end{array}$ &.---- & $--\cdot-$ &.---- &.---- & $\begin{array}{l}111.71 \\
{[0.000]}\end{array}$ &.---- & $\begin{array}{c}6.94 \\
{[0.000]}\end{array}$ & $--\cdot-$ \\
\hline Cut test: $\mathrm{T} 1=\mathrm{T} 2$ & $\begin{array}{l}697.04 \\
{[0.000]}\end{array}$ & $\begin{array}{l}749.55 \\
{[0.000]}\end{array}$ & $\begin{array}{l}760.38 \\
{[0.000]}\end{array}$ & $\begin{array}{l}783.49 \\
{[0.000]}\end{array}$ & $\begin{array}{l}734.12 \\
{[0.000]}\end{array}$ & $--\cdot--$ & $--\cdot--$ &.---- \\
\hline Cut test: $\mathrm{T} 2=\mathrm{T} 3$ & $\begin{array}{l}774.32 \\
{[0.000]}\end{array}$ & $\begin{array}{l}804.75 \\
{[0.000]}\end{array}$ & $\begin{array}{l}808.11 \\
{[0.000]}\end{array}$ & $\begin{array}{l}814.97 \\
{[0.000]}\end{array}$ & $\begin{array}{l}769.71 \\
{[0.000]}\end{array}$ & $--\cdot--$ & $--\cdot--$ &.---- \\
\hline Provincial dummies & NO & YES & YES & YES & YES & NO & YES & YES \\
\hline Historical turnout & NO & NO & YES & YES & YES & NO & YES & YES \\
\hline Contextual variables & NO & NO & NO & YES & YES & NO & YES & YES \\
\hline Individual variables & NO & NO & NO & NO & YES & NO & YES & NO \\
\hline Treated & 160 & 160 & 160 & 160 & 160 & 160 & 160 & 160 \\
\hline Control & 131 & 131 & 131 & 131 & 131 & 131 & 131 & 131 \\
\hline Observations & 6,902 & 6,902 & 6,902 & 6,902 & 6,902 & 6,902 & 6,902 & 291 \\
\hline
\end{tabular}

Notes: (1) Dependent variable: Trust in local politicians: 4=High trust. 3=Medium-High. 2=Medium-Low. 1=Low; or Corruption perception: 4=High corruption, 3=Medium-High, 2=Medium-Low, 1=Low. (2) Standard errors clustered at the municipal level in parentheses, ${ }^{* * *}: p<0.01 .{ }^{* *} p<0.05$. * $: p<0.1$. (3) Estimation method columns (i) - (iv) Maximum Likelihood; (vi) to (viii) OLS. (4) Thresholds tests: test indicating whether the cuts delimiting two contiguous categories are equal, meaning it is possible to reduce the number of categories. p-values in brackets. (5) Dependent variable columns (vi-vii) 1if high or medium high trust (or corruption perception) 0 if medium-low or low trust (or corruption perception); (vii) share of individuals with high or medium-high trust or corruption perception in a given municipality. 
Table 2: Marginal effects of corruption

\begin{tabular}{|c|c|c|c|c|}
\hline \multirow[b]{2}{*}{ Categories: } & \multicolumn{4}{|c|}{ (a) Trust in local politicians } \\
\hline & $\begin{array}{l}(1) \\
\text { Low }\end{array}$ & $\begin{array}{c}(2) \\
\text { Medium- } \\
\text { low }\end{array}$ & $\begin{array}{l}(3) \\
\text { Medium- } \\
\text { high }\end{array}$ & $\begin{array}{c}(4) \\
\text { High }\end{array}$ \\
\hline (a) Marginal effect & $0.047^{* * *}$ & $0.016^{* * *}$ & $-0.040^{* * *}$ & $-0.022^{* * *}$ \\
\hline (b) Prob. $($ Trust $=j \mid$ Corruption $=0$ ) & 0.214 & 0.320 & 0.360 & 0.106 \\
\hline \multirow[t]{3}{*}{ Effect in \% = (a) / (b) } & 22.0 & 5.0 & -11.1 & -20.8 \\
\hline & \multicolumn{4}{|c|}{ (b) Corruption perception } \\
\hline & $\begin{array}{c}(1) \\
\text { Low }\end{array}$ & $\begin{array}{l}(2) \\
\text { Medium- } \\
\text { low }\end{array}$ & $\begin{array}{l}\text { (3) } \\
\text { Medium- } \\
\text { high }\end{array}$ & $\begin{array}{c}(4) \\
\text { High }\end{array}$ \\
\hline (a) Marginal effect & $-0.054^{* * *}$ & $-0.022^{* * *}$ & $0.046^{* * *}$ & $0.029^{* * *}$ \\
\hline (b) Prob.(C. perception $=j \mid C .=0$ ) & 0.249 & 0.339 & 0.322 & 0.089 \\
\hline Effect in $\%=(\mathrm{a}) /(\mathrm{b})$ & -21.7 & -6.5 & 14.3 & 32.6 \\
\hline
\end{tabular}

Notes: (1) Marginal effects on trust computed using the results of column (v), Table 1 (2) Marginal effects on corruption perception computed using the results of column (v), Table 1.

Table 3: Falsification tests

\begin{tabular}{|l|cc|cc|c|}
\hline \multirow{7}{*}{} & \multicolumn{2}{|c|}{$\begin{array}{c}\text { (i) Scandal after } \\
\text { the survey? }\end{array}$} & $\begin{array}{c}\text { (ii) Moving in } \\
\text { before the scandal? }\end{array}$ & $\begin{array}{c}\text { (iii) Exposed to } \\
\text { the scandal? }\end{array}$ \\
& NO & YES & NO & YES & NO \\
\cline { 2 - 6 } & (i) & (ii) & (iii) & (iv) & $(\mathrm{v})$ \\
\hline \multicolumn{7}{|c|}{ (a) Trust } \\
\hline Corruption & $-0.266^{* * *}$ & -0.001 & $-0.253^{* * *}$ & $-0.436^{* * *}$ & -0.080 \\
& $(0.080)$ & $(0.243)$ & $(0.086)$ & $(0.168)$ & $(0.360)$ \\
\hline \multicolumn{7}{|c|}{ (b) Corruption perception } \\
\hline Corruption & $0.325^{* * *}$ & 0.045 & $0.308^{* * *}$ & $0.807^{* * *}$ & 0.104 \\
& $(0.099)$ & $(0.212)$ & $(0.105)$ & $(0.193)$ & $(0.338)$ \\
\hline $\begin{array}{l}\text { Provincial dummies } \\
\text { Historical turnout }\end{array}$ & YES & YES & YES & YES & YES \\
Contextual variables & YES & YES & YES & YES & YES \\
Individual variables & YES & YES & YES & YES & YES \\
\hline Treated municipalities & 160 & 40 & 160 & YES \\
Control municipalities & 131 & 31 & 131 & 89 & 60 \\
Observations & 6,902 & 1,853 & 5,963 & 787 & 585 \\
\hline
\end{tabular}

Notes: (1) Scandal breakout after the survey? = YES if the scandal breakout after the survey was conducted and NO if this is not the case; Moving in before the scandal = YES if the individual was above voting age at when the scandal broke out and moved into the municipality less than five years before and NO if the individual was above voting age and lived in the community at the time of the scandal but moved in more than five years before; Exposed to the scandal = NO if the individual was below the voting age when the scandal broke out and or lived in another municipality, (2). The estimation method is an Ordered Logit. (3) All controls included: provincial dummies, historical turnout, contextual an individual variables. (4) For sake of comparability, columns (i) report the results shown in column (v) in Table 1. 
Table 4: Effects of Time elapsed since the scandal broke out

\begin{tabular}{|c|c|c|c|c|c|c|}
\hline & \multicolumn{3}{|c|}{ Ordered Logit } & \multicolumn{3}{|c|}{ OLS } \\
\hline \multicolumn{7}{|c|}{ (a) Trust } \\
\hline & (i) & (ii) & (iii) & (iv) & (v) & (v) \\
\hline Corruption & $\begin{array}{c}-0.266^{* * *} \\
(0.080)\end{array}$ & $\begin{array}{l}-0.235^{* *} \\
(0.106)\end{array}$ & $\begin{array}{l}-0.239^{*} \\
(0.124)\end{array}$ & $\begin{array}{l}-0.065^{* * *} \\
(0.020)\end{array}$ & $\begin{array}{l}-0.069^{* *} \\
(0.038)\end{array}$ & $\begin{array}{l}-0.068^{* *} \\
(0.039)\end{array}$ \\
\hline $\begin{array}{l}\text { Corruption } \\
\times \text { Time since scandal }\end{array}$ & $--\cdot-$ & $\begin{array}{c}0.008 \\
(0.018)\end{array}$ & $\begin{array}{c}0.007 \\
(0.018)\end{array}$ & $-\cdots-\cdot$ & $\begin{array}{c}0.001 \\
(0.005)\end{array}$ & $\begin{array}{c}0.001 \\
(0.006)\end{array}$ \\
\hline \multicolumn{7}{|c|}{ (b) Corruption perception } \\
\hline Corruption & $\begin{array}{l}0.325^{* * *} \\
(0.099)\end{array}$ & $\begin{array}{l}0.461^{* * *} \\
(0.085)\end{array}$ & $\begin{array}{l}0.484^{* * *} \\
(0.100)\end{array}$ & $\begin{array}{l}0.067^{* * *} \\
(0.024)\end{array}$ & $\begin{array}{l}0.069^{* * *} \\
(0.021)\end{array}$ & $\begin{array}{l}0.070^{* * *} \\
(0.024)\end{array}$ \\
\hline $\begin{array}{l}\text { Corruption } \\
\times \text { Time since scandal }\end{array}$ &.---- & $\begin{array}{l}-0.035^{* *} \\
(0.015)\end{array}$ & $\begin{array}{l}-0.036^{* *} \\
(0.015)\end{array}$ & $--\cdot--$ & $\begin{array}{l}-0.006^{* *} \\
(0.003)\end{array}$ & $\begin{array}{l}-0.006^{*} \\
(0.004)\end{array}$ \\
\hline Provincial dummies & YES & YES & YES & YES & YES & YES \\
\hline Historical turnout & YES & YES & YES & YES & YES & YES \\
\hline Contextual variables & YES & YES & YES & YES & YES & YES \\
\hline Individual variables & YES & YES & YES & YES & YES & YES \\
\hline Corruption traits & NO & NO & YES & NO & NO & YES \\
\hline Treated municipalities & 160 & 160 & 160 & 160 & 160 & 160 \\
\hline Control municipalities & 131 & 131 & 131 & 131 & 131 & 131 \\
\hline Observations & 6,902 & 6,902 & 6,902 & 6,902 & 6,902 & 6,902 \\
\hline
\end{tabular}

Note: (1) Corruption traits is a dummy equal to 1 if the press coverage has been particularly high (i.e., equal to one if the number of news stories are higher than the ones than can be expected for a municipality of that size). 
Table 5: Effect of corruption on potential mediators. OLS estimates.

\begin{tabular}{|c|c|c|c|c|c|c|c|c|c|c|c|}
\hline & \multirow{2}{*}{$\begin{array}{l}\text { Corruption } \\
\text { perception } \\
\text { (i) }\end{array}$} & \multicolumn{2}{|c|}{ Fragmentation } & \multicolumn{6}{|c|}{ Fiscal stress } & \multicolumn{2}{|c|}{ (iv) Development } \\
\hline & & $\begin{array}{c}\text { Majority } \\
\text { (ii) }\end{array}$ & $\begin{array}{c}\text { HH index } \\
\text { (iii) } \\
\end{array}$ & $\begin{array}{l}\text { Capital } \\
\text { grants } \\
\text { (iv) }\end{array}$ & $\begin{array}{c}\text { Taxes } \\
(\mathrm{v})\end{array}$ & $\begin{array}{c}\text { Deficit } \\
\text { (vi) }\end{array}$ & $\begin{array}{c}\text { Current } \\
\text { grants } \\
\text { (vii) }\end{array}$ & $\begin{array}{c}\text { Current } \\
\text { spending } \\
\text { (viii) }\end{array}$ & $\begin{array}{c}\text { Capital } \\
\text { spending } \\
\text { (ix) }\end{array}$ & $\begin{array}{l}\text { Unemploy- } \\
\text { ment rate } \\
(\mathrm{x})\end{array}$ & $\begin{array}{l}\text { Population } \\
\text { growth } \\
\text { (xi) }\end{array}$ \\
\hline \multicolumn{12}{|c|}{ (a) Average effect } \\
\hline Corruption & $\begin{array}{c}0.071 \\
(0.025)^{* * *}\end{array}$ & $\begin{array}{c}-0.196 \\
(0.098)^{* *}\end{array}$ & $\begin{array}{c}-0.021 \\
(0.009)^{* *}\end{array}$ & $\begin{array}{c}-0.091 \\
(0.052)^{* *}\end{array}$ & $\begin{array}{c}0.118 \\
(0.035)^{* *}\end{array}$ & $\begin{array}{c}0.038 \\
(0.032)\end{array}$ & $\begin{array}{c}0.026 \\
(0.027)\end{array}$ & $\begin{array}{c}0.021 \\
(0.028)\end{array}$ & $\begin{array}{c}0.082 \\
(0.054)\end{array}$ & $\begin{array}{l}-0.108 \\
(0.493)\end{array}$ & $\begin{array}{c}0.090 \\
(0.194)\end{array}$ \\
\hline $\mathrm{R}^{2}$ & 0.030 & 0.492 & 0.615 & 0.438 & 0.804 & 0.297 & 0.602 & 0.709 & 0.370 & 0.735 & 0.860 \\
\hline \multicolumn{12}{|c|}{ (b) Time since scandal } \\
\hline Corruption & $\begin{array}{c}0.071 \\
(0.025)^{* * *}\end{array}$ & $\begin{array}{c}-0.198 \\
(0.086)^{*}\end{array}$ & $\begin{array}{c}-0.022 \\
(0.009)^{* *}\end{array}$ & $\begin{array}{c}-0.092 \\
(0.075)^{*}\end{array}$ & $\begin{array}{c}0.112 \\
(0.046)^{* *}\end{array}$ & $\begin{array}{c}0.040 \\
(0.022)^{*}\end{array}$ & $\begin{array}{c}0.026 \\
(0.037)\end{array}$ & $\begin{array}{c}0.020 \\
(0.038)\end{array}$ & $\begin{array}{c}0.079 \\
(0.049)\end{array}$ & $\begin{array}{l}-0.107 \\
(0.466)\end{array}$ & $\begin{array}{c}0.091 \\
(0.200)\end{array}$ \\
\hline $\begin{array}{l}\text { Corruption } \\
\times \text { Time since scandal }\end{array}$ & $\begin{array}{c}-0.006 \\
(0.003)^{*}\end{array}$ & $\begin{array}{l}-0.007 \\
(0.018)\end{array}$ & $\begin{array}{c}-0.002 \\
(0.002)^{*}\end{array}$ & $\begin{array}{c}0.005 \\
(0.015)\end{array}$ & $\begin{array}{c}0.008 \\
(0.005)^{* *}\end{array}$ & $\begin{array}{l}-0.002 \\
(0.002)\end{array}$ & $\begin{array}{c}0.002 \\
(0.007)\end{array}$ & $\begin{array}{l}-0.002 \\
(0.006)\end{array}$ & $\begin{array}{c}0.004 \\
(0.013)\end{array}$ & $\begin{array}{l}-0.031 \\
(0.237)\end{array}$ & $\begin{array}{c}0.036 \\
(0.075)\end{array}$ \\
\hline $\mathrm{R}^{2}$ & 0.036 & 0.491 & 0.623 & 0.440 & 0.809 & 0.298 & 0.602 & 0.715 & 0.379 & 0.733 & 0.860 \\
\hline
\end{tabular}


Table 6: Effect of potential mediators on Trust. OLS estimates.

\begin{tabular}{|c|c|c|c|c|c|c|}
\hline & (i) & (ii) & (iii) & (iv) & (v) & (vi) \\
\hline \multicolumn{7}{|c|}{ (a) Average effect } \\
\hline Corruption perception & $\begin{array}{c}-0.318 \\
(0.027)^{* * *}\end{array}$ & $--\cdot--$ &.---- &.---- & $\begin{array}{c}-0.310 \\
(0.027)^{* * *}\end{array}$ &.---- \\
\hline HH index &.---- & $\begin{array}{c}0.695 \\
(0.148)^{* * *}\end{array}$ & $--\cdot--$ & $--\cdot--$ & $\begin{array}{c}0.541 \\
(0.114)^{* * *}\end{array}$ & $--\cdot-$ \\
\hline Taxes & $-\cdot-\cdot$ & --.-- & $\begin{array}{c}-0.097 \\
(0.027)^{* *}\end{array}$ & $--\cdot--$ & $\begin{array}{c}-0.118 \\
(0.029)^{* *}\end{array}$ &.---- \\
\hline Deficit &.---- & $--\cdot--$ & $--\cdot--$ & $\begin{array}{l}-0.068 \\
(0.061)\end{array}$ & $\begin{array}{c}-0.038 \\
(0.018)\end{array}$ &.---- \\
\hline Corruption & $\begin{array}{c}-0.053 \\
(0.017)^{* * *}\end{array}$ & $\begin{array}{c}-0.059 \\
(0.020)^{* * *}\end{array}$ & $\begin{array}{c}-0.064 \\
(0.019)^{* * *}\end{array}$ & $\begin{array}{c}-0.070 \\
(0.021)^{* * *}\end{array}$ & $\begin{array}{c}-0.027 \\
(0.011)^{* * *}\end{array}$ & $\begin{array}{c}-0.069 \\
(0.027)^{* * *}\end{array}$ \\
\hline $\mathrm{R}^{2}$ & 0.129 & 0.040 & 0.034 & 0.033 & 0.133 & 0.032 \\
\hline \multicolumn{7}{|c|}{ (b) Time since scandal } \\
\hline Corruption perception & $\begin{array}{c}-0.314 \\
(0.027)^{* * *}\end{array}$ &.---- &.---- &.---- & $\begin{array}{c}-0.300 \\
(0.026)^{* * *}\end{array}$ &.---- \\
\hline HH index &.---- & $\begin{array}{c}0.684 \\
(0.133)^{* * *}\end{array}$ &.---- &.---- & $\begin{array}{c}0.541 \\
(0.129)^{* * *}\end{array}$ &.---- \\
\hline Taxes &.---- & $--\cdot--$ & $\begin{array}{c}-0.092 \\
(0.031)^{* *}\end{array}$ &.---- & $\begin{array}{c}-0.102 \\
(0.055)^{*}\end{array}$ &.---- \\
\hline Deficit &.---- & $--\cdot--$ & $--\cdot-$ & $\begin{array}{l}-0.062 \\
(0.059)\end{array}$ & $\begin{array}{c}-0.036 \\
(0.017)\end{array}$ &.---- \\
\hline Corruption & $\begin{array}{c}-0.053 \\
(0.017)^{* * *}\end{array}$ & $\begin{array}{c}-0.058 \\
(0.020)^{* * *}\end{array}$ & $\begin{array}{c}-0.067 \\
(0.020)^{* * *}\end{array}$ & $\begin{array}{c}-0.070 \\
(0.021)^{* * *}\end{array}$ & $\begin{array}{l}-0.026 \\
(0.023)\end{array}$ & $\begin{array}{c}-0.065 \\
\left(0.033^{* *}\right.\end{array}$ \\
\hline $\begin{array}{l}\text { Corruption } \\
\times \text { Time since scandal }\end{array}$ & $\begin{array}{l}-0.001 \\
(0.004)\end{array}$ & $\begin{array}{c}0.001 \\
(0.005)\end{array}$ & $\begin{array}{c}0.001 \\
(0.005)\end{array}$ & $\begin{array}{c}-0.001 \\
(0.005)\end{array}$ & $\begin{array}{c}0.001 \\
(0.004)\end{array}$ & $\begin{array}{c}0.001 \\
(0.005)\end{array}$ \\
\hline $\mathrm{R}^{2}$ & 0.129 & 0.040 & 0.034 & 0.033 & 0.133 & 0.032 \\
\hline
\end{tabular}

Notes: (1) The dependent variable is Trust, measured as a high v. low dummy. (2) Columns (i) to (iv) report the results obtained when introducing one 'mediator' at a time; column (v) report the results obtained when introducing all the 'mediators' at the same time; column (vi) reports the total effect of corruption on trust. (3) Panel (a) report the effect of each mediator when the effect of corruption is not allowed to vary over time; Panel (b) allows corruption to interact with Time since scandal. (4) Standard errors clustered at the municipal level in parentheses, ${ }^{* * *}: p<0.01$. ${ }^{* *} p<0.05$. $^{*}: p<0.1$. 
Table 7: Mediation analysis

\begin{tabular}{|c|c|c|c|}
\hline & ACME & $\%$ Mediated & $\begin{array}{l}\text { ACME range } \\
0 / 9 \text { years since } \\
\text { the scandal }\end{array}$ \\
\hline \multicolumn{4}{|c|}{ (a) Mediation effects } \\
\hline Corruption perception & $\begin{array}{c}-0.022 \\
{[-0.008,-0.036]}\end{array}$ & $31.9 \%$ & $\begin{array}{c}-0.031 /-0.011 \\
{[43.8 \% / 17.6 \%]}\end{array}$ \\
\hline HH index & $\begin{array}{c}-0.011 \\
{[-0.007,-0.016)}\end{array}$ & $16.5 \%$ & $\begin{array}{c}-0.008 /-0.017 \\
{[12.1 \% \% / 26.5 \%]}\end{array}$ \\
\hline Taxes & $\begin{array}{c}-0.008 \\
{[-0.001,-0.015]}\end{array}$ & $11.8 \%$ & $\begin{array}{c}-0.005 /-0.010 \\
{[6.7 \% / 15.7 \%]}\end{array}$ \\
\hline Deficit & $\begin{array}{c}-0.001 \\
{[0.001,-0.004)}\end{array}$ & $2.1 \%$ & $\begin{array}{l}-0.001 /-0.002 \\
{[1.6 \% / 2.6 \%]}\end{array}$ \\
\hline \multicolumn{4}{|c|}{ (b) Direct effects } \\
\hline Corruption & $\begin{array}{c}-0.027 \\
{[-0.003,-0.041]}\end{array}$ & $37.7 \%$ & $\begin{array}{c}-0.027 /-0.027 \\
{[38.8 \% / 42.8 \%]}\end{array}$ \\
\hline
\end{tabular}

Notes: (1) ACME=average causal mediation effect, computed using the cell corresponding to each 'mediator' in column (v) in Table 6 and in Table 5; the value corresponding to the corruption line is the direct effect while the other results are the effects mediated by each of the other variables considered; in brackets we show the $90 \%$ c.i. (2) \% Mediated is the ratio between the ACME and the Total effect, reported in column (vi) in Table 6. (3) ACME Range: value of the ACME for the minimum and maximum values of time (i.e., zero and nine; in brackets we show the $\%$ mediated by each variable at years zero and nine.

Figure 1: Effects of corruption on trust and corruption perception $v$. Time since the scandal

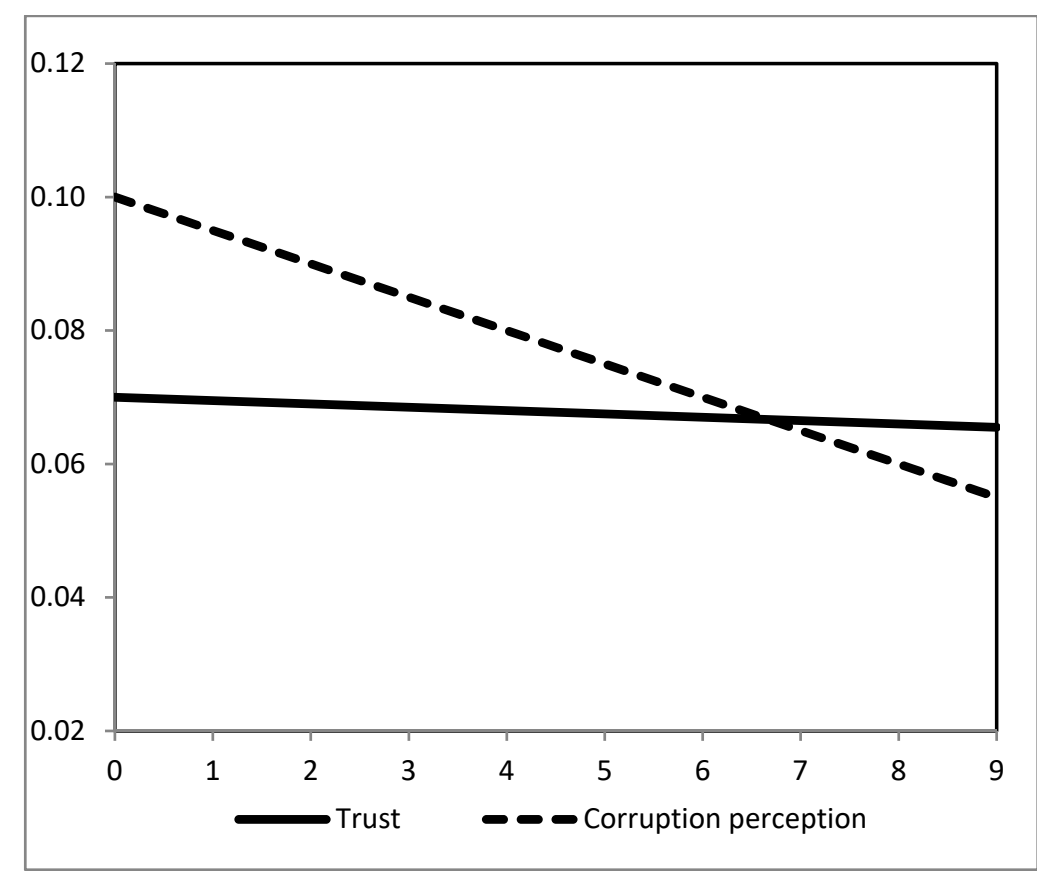

Notes: (1) Marginal effect of corruption on Trust and Corruption perception as a function of the number of Time since scandal (in years). (2) In this graph the sign of the trust coefficient is reverted. 
Figure2: Mediation diagram

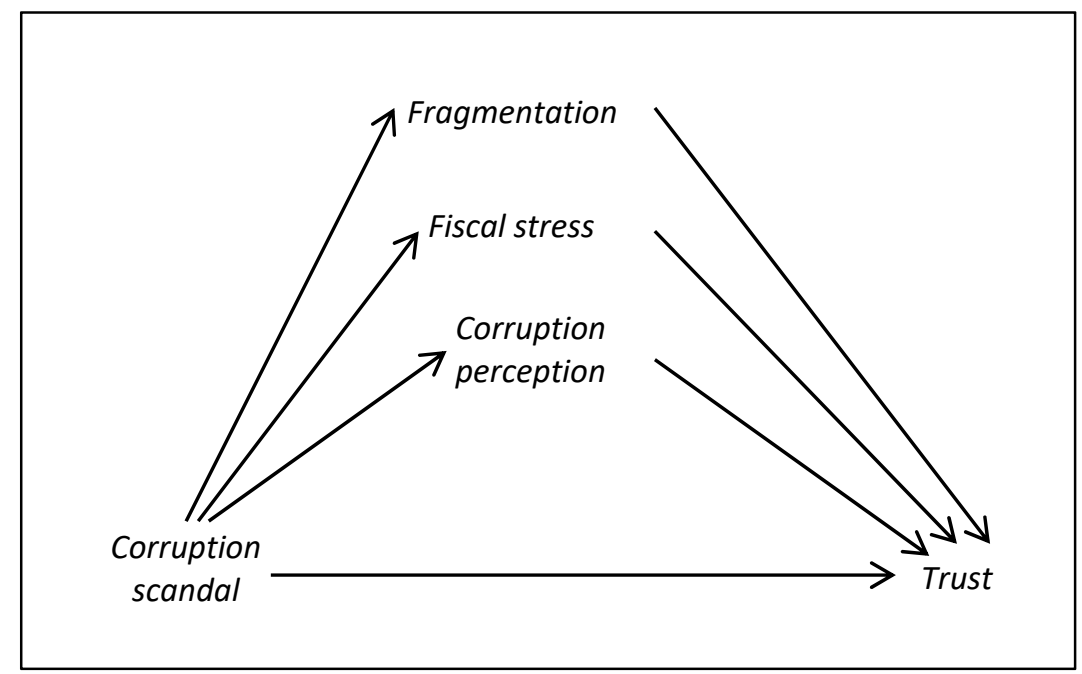

Figure 3: Effects of corruption on trust net of the impact on fiscal stress and fragmentation

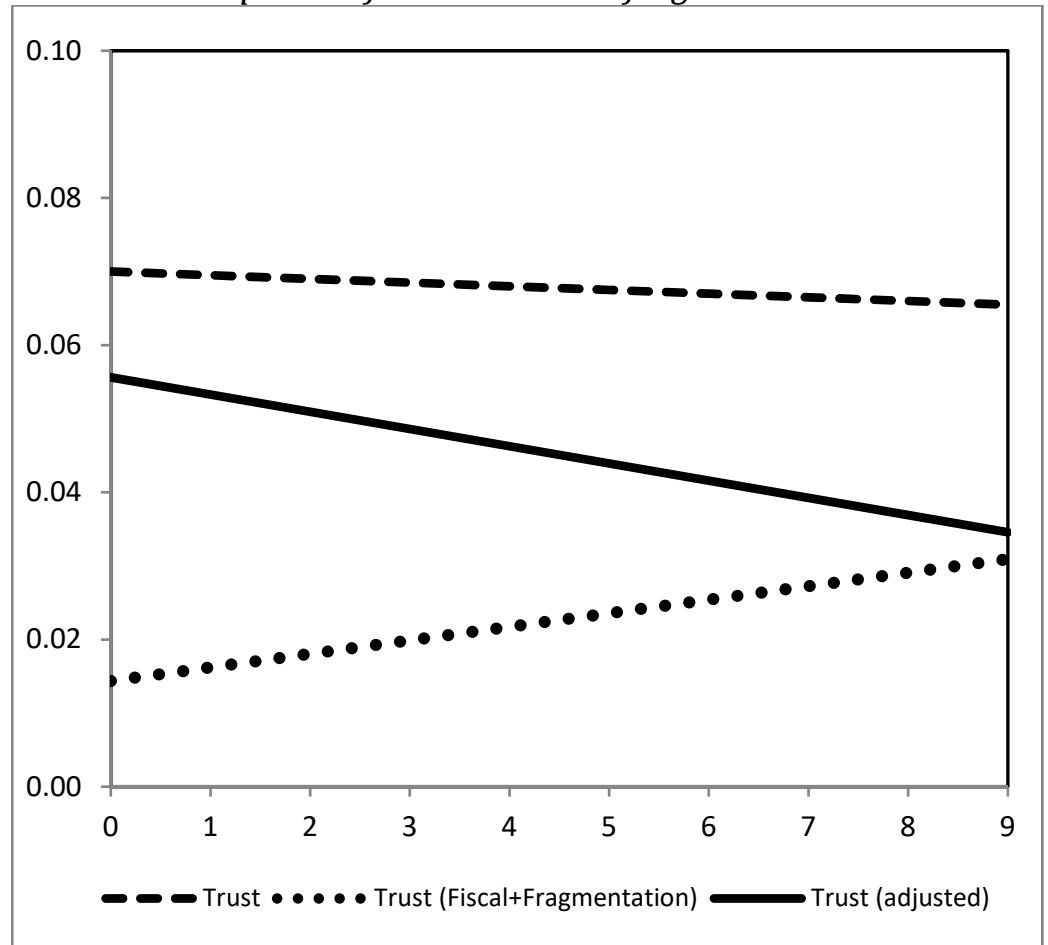

Notes: (1) Marginal effect of corruption on Trust before and after the adjusting for the effects on Fiscal stress and on Fragmentation; (2) Trust = effects before adjustment, Trust (adjusted) = effects after adjustment; Trust (Fiscal + Fragmentation) $=$ ACME of the Fiscal Stress and Fragmentation mediator variables. (3) In this graph the sign of the coefficients is reverted. 


\section{Appendix}

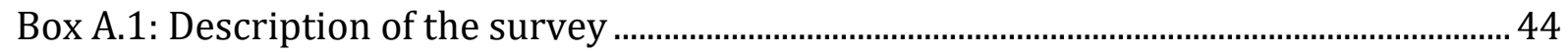

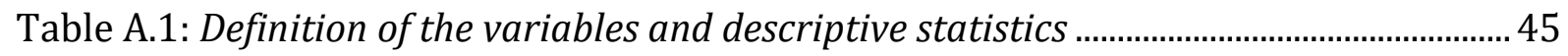

Table A.2: Determinants of corruption. Probit estimation........................................................... 46

Table A.3. Comparison of alternative matching procedures ....................................................... 46

Table A.4: Differences in means between Treated and Control groups. Contextual variables used in the matching procedure.

Table A.5. Differences in means between Treated and Control groups. Contextual variables used in the matching procedure. Alternative matching procedures. 48

Table A.6. Differences in means between Treated and Control groups. Contextual variables used in the matching procedure. Subsamples.

Table A.7: Differences in means between Treated and Control groups. Individual variables obtained from the survey. 50

Table A.8: Differences in means between Treated and Control groups. Individual variables obtained from the survey. Subsamples. 51

Table A.9: Selective attrition and sorting 52

Table A.10: Effects of corruption scandals on trust in local politicians. Sensitivity checks. 52

Figure A.1: Share of population that identifies corruption and fraud as being among

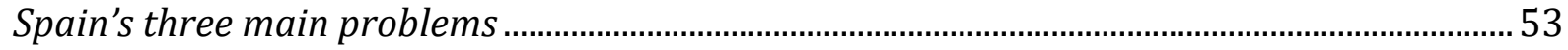

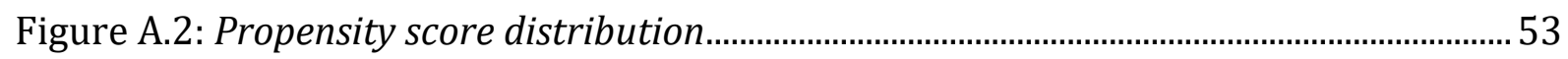

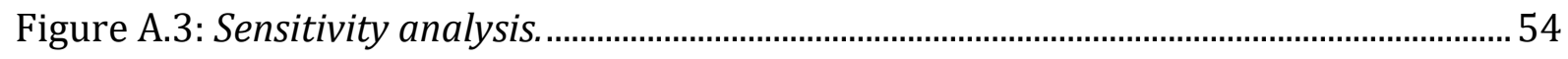

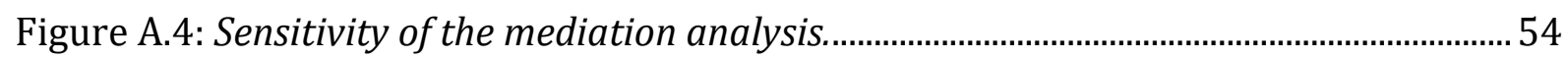


"Treball de Camp", a firm specialising in the design and implementation of surveys, conducted the survey. The interviews were conducted by telephone during December 2009. Due to budget constraints, it was not possible to include all the municipalities in which at least one corruption scandal had been reported during the period 1999-2009 plus their matched pair. Thus, a representative sample of municipalities was selected, composed of 160 corrupt and 131 non-corrupt municipalities. The sample is representative with regard to three specific dimensions: i) the timing of the corruption scandal; ii) municipality size (in terms of population); iii) and geographical location of the municipalities (by province). The number of individuals interviewed varied according to municipality size: 20 individuals were interviewed in municipalities with fewer than 10,000 inhabitants; 40 if $10.000<$ Population $\leq$ 100.000; 50 if 100.000<Population $\leq 500.000$; and 100 if Population $>500.000$. The final sample included 9060 interviews. The sample was also representative in terms of individual characteristics (gender and age) for the whole Spanish population and by municipality size.

The survey included residents older than 18 years at the moment of the survey that could vote in local elections (i.e. natives or EU immigrants).

To guarantee a high response rate, we designed survey to be completed in five minutes. To avoid any conditioning of responses the answer, the survey was organized as follows:

- Before starting the survey, a set of basic filter questions (gender, age, nationality and municipality in which the individual is registered) were used to obtain a representative sample;

- First bloc: it includes questions regarding trust

- Second bloc: it includes questions concerning voting decisions and information about the individual

- Third bloc: it includes questions regarding corruption perceptions

- Fourth bloc: it includes questions regarding socio-demographic characteristics 
Table A.1: Definition of the variables and descriptive statistics

\begin{tabular}{|c|c|c|c|}
\hline Variable & Definition & Mean & St.Dev. \\
\hline \multicolumn{4}{|c|}{ Individual-level variables } \\
\hline Trust & Question (1-4); 1: Never; 2: Rarely; 3: Most of the time; 4: Always & 2.259 & 0.925 \\
\hline Corruption perception & Question (1-4): 1: Low, 2: Medium-low; 3: Medium-high; 4: High & 2.358 & 0.941 \\
\hline Income & $\begin{array}{l}\text { Self-reported socio-economic classification (1-5): 1: Low; } \\
\text { 2: Medium-low; 3: Medium; 4: Medium-High; 5: High }\end{array}$ & 2.754 & 0.799 \\
\hline Education & $\begin{array}{l}\text { Highest level of education completed (1-5) } \\
\text { 1: any studies; } 2 \text { : primary; } 3 \text { : secondary; } 4 \text { : graduate }\end{array}$ & 3.232 & 1.275 \\
\hline Age & Age in years & 45.46 & 17.220 \\
\hline Female & Dummy variable coded 1 for females & $0.49 \overline{9}$ & 0.500 \\
\hline Divorced & Dummy variable coded 1 for people who are divorced or separated & 0.042 & 0.200 \\
\hline Unemployed & Dummy variable coded 1 for people who are unemployed & 0.135 & 0.342 \\
\hline Student & Dummy variable coded 1 for students (do not work) & 0.084 & 0.278 \\
\hline Retired & Dummy variable coded 1 for people who are retired & 0.205 & 0.404 \\
\hline Immigrant & Dummy variable coded 1 for people who are not born in Spain & 0.043 & 0.202 \\
\hline \multicolumn{4}{|c|}{ Contextual-level variables (used in the matching procedure) } \\
\hline Corruption & $\begin{array}{l}\text { Dummy variable coded } 1 \text { for municipalities with at least one } \\
\text { corruption scandal in the period } 1999-2009\end{array}$ & 0.584 & 0.493 \\
\hline$\%$ Turnout & Average vote turnout at the 1987,1991 and 1995 local elections & 0.707 & 0.091 \\
\hline Income p.c. & $\begin{array}{l}\text { Average socio-economic condition. Arithmetic average of the socio- } \\
\text { economic condition according to their employment status }\end{array}$ & 0.941 & 0.146 \\
\hline$\%$ Divorced & Percentage of divorced and separated among all population & 0.020 & 0.011 \\
\hline$\%$ Graduate & $\begin{array}{l}\text { Percentage of population with third level studies (diploma, degree } \\
\text { and doctorate) among population } 16 \text { years and older }\end{array}$ & 0.082 & 0.048 \\
\hline \% Unemployed & Percentage of unemployed among individuals aged 20-59 & 0.144 & 0.105 \\
\hline Ethnic diversity & $\begin{array}{l}1-\Sigma_{k}\left(\text { Pop }_{k} / \text { Population }\right)^{2} \text { where Pop_cont } t_{k} \text { is population whose } \\
\text { nationality is from continent } k \text {, and } k \text { refers to Europe, Africa, }\end{array}$ & 0.039 & 0.048 \\
\hline$\%$ Right voters & $\begin{array}{l}\text { Average historical vote share that the right wing parties obtained at } \\
\text { the } 1987,1991 \text { and } 1995 \text { local elections }\end{array}$ & 0.406 & 0.096 \\
\hline Log(Population $)$ & Log of the registered population & 8.428 & 1.190 \\
\hline \multicolumn{4}{|c|}{ Contextual-level variables (used in the robustness checks) } \\
\hline$\%$ Provincial turnout & $\begin{array}{l}\text { Average vote turnout at the 1987, } 1991 \text { and } 1995 \text { local elections in } \\
\text { the respective province }\end{array}$ & 0.702 & 0.085 \\
\hline$\% \Delta$ Turnout & Change in the local turnout between the 1987 and 1995 elections & -0.055 & 0.087 \\
\hline Newspapers p.c. & Per day average number of newspapers sold in a province per capita & 0.094 & 0.029 \\
\hline Associations p.c. & Number of associations in a province per capita & 0.005 & 0.001 \\
\hline$\% \Delta$ Population & Population growth between 1991 and 2001, in percentage terms. & 0.148 & 0.116 \\
\hline$\%$ Vacation houses & Percentage of houses that are vacation houses & 0.199 & 0.175 \\
\hline
\end{tabular}

Notes: (1) Source of the individual-level variables: own-designed survey (see Box A.1). (2) Sources of the contextuallevel variables: (i) 2001 Census of Population (National Institute of Statistics, www.ine.es), for Income p.c., \% Divorced, $\%$ \%Graduate, \% Unemployed, population by continent used to construct the Ethnic diversity index, and Population. (ii) Database on corruption scandals, constructed form an initial list of scandals compiled by Fundación Alternativas and own Internet searches (see section 3 for more details). (iii) Voting data from the Ministry of the Interior, used for the construction of the \% Right voters and \% Turnout variables. 
Table A.2: Determinants of corruption. Probit estimation.

\begin{tabular}{|l|cc|}
\hline & Coef. & z-stat. \\
\hline \% Turnout & 0.653 & $(20.31)^{* * *}$ \\
Income per capita & -1.451 & $(-3.53)^{* * *}$ \\
\% Divorced & 12.502 & $(3.18)^{* * *}$ \\
\% Graduate & 2.337 & $(3.03)^{* * *}$ \\
\% Unemployed & 0.809 & $(1.73)^{*}$ \\
Ethnic diversity & 2.620 & $(3.72)^{* * *}$ \\
\% Right voters & 1.728 & $(4.76)^{* * *}$ \\
Log(population) & 0.495 & $(16.12)^{* * *}$ \\
Constant & -4.980 & $(-9.78)^{* * *}$ \\
\hline \multicolumn{1}{|c|}{ Pseudo-R ${ }^{2}$} & \multicolumn{3}{|c|}{0.237} \\
\hline
\end{tabular}

Note: (1) Dependent variable is Corruption (dummy equal to one if a corruption scandal broke out in the municipality between 1999 and end of 2009). (2) Final specification: only variables statistically significant at the $90 \%$ level are kept.

Table A.3. Comparison of alternative matching procedures

\begin{tabular}{|c|c|c|c|c|c|}
\hline & \multirow[b]{2}{*}{ Unmatched } & \multicolumn{4}{|c|}{ Matched } \\
\hline & & $\begin{array}{c}\text { 'nearest } \\
\text { neighbor with } \\
\text { replacement' }\end{array}$ & $\begin{array}{c}\text { 'nearest } \\
\text { neighbor one- } \\
\text { to-one' }\end{array}$ & 'kernel' & $\begin{array}{c}\text { 'radius' } \\
\text { caliper(0.03) }\end{array}$ \\
\hline Pseudo-R2 & 0.237 & 0.002 & 0.017 & 0.003 & 0.003 \\
\hline LR-Chi2 & $\begin{array}{r}624.25 \\
{[0.000]}\end{array}$ & $\begin{array}{r}2.32 \\
{[0.940]}\end{array}$ & $\begin{array}{r}23.74 \\
{[0.001]}\end{array}$ & $\begin{array}{r}3.79 \\
{[0.804]}\end{array}$ & $\begin{array}{r}4.31 \\
{[0.744]}\end{array}$ \\
\hline Mean bias & 42.2 & 2.5 & 11.4 & 4.7 & 5.4 \\
\hline Median bias & 46.7 & 2.2 & 11.5 & 5.0 & 4.1 \\
\hline
\end{tabular}


Table A.4: Differences in means between Treated and Control groups. Contextual variables used in the matching procedure.

\begin{tabular}{|c|c|c|c|}
\hline & \multicolumn{2}{|c|}{ Mean } & \multirow{2}{*}{$\begin{array}{c}\text { t-test } \\
{[\mathrm{p} \text {-value }]}\end{array}$} \\
\hline & Treated & Control & \\
\hline \multicolumn{4}{|c|}{ Unmatched sample } \\
\hline$\%$ Turnout & 0.741 & 0.754 & $4.25[0.000]$ \\
\hline Income p.c. & 0.947 & 0.939 & $1.09[0.282]$ \\
\hline$\%$ Divorced & 0.026 & 0.018 & 14.09 [0.000] \\
\hline$\%$ College & 0.106 & 0.077 & $12.57[0.000]$ \\
\hline$\%$ Unemployment & 0.147 & 0.143 & $0.88[0.381]$ \\
\hline Ethnic diversity & 0.060 & 0.035 & $10.83[0.002]$ \\
\hline$\%$ Right voters & 0.507 & 0.505 & $0.36[0.724]$ \\
\hline $\log ($ Population $)$ & 9.610 & 8.182 & $2.731[0.003]$ \\
\hline \multicolumn{4}{|c|}{ Matched sample } \\
\hline$\%$ Turnout & 0.741 & 0.737 & $0.54[0.683]$ \\
\hline Income p.c. & 0.946 & 0.942 & $0.47[0.642]$ \\
\hline$\%$ Divorced & 0.026 & 0.026 & $-0.12[0.915]$ \\
\hline$\%$ College & 0.105 & 0.105 & $0.19[0.853]$ \\
\hline$\%$ Unemployment & 0.147 & 0.150 & $-0.40[0.694]$ \\
\hline Ethnic diversity & 0.060 & 0.057 & $0.86[0.390]$ \\
\hline$\%$ Right voters & 0.507 & 0.509 & $-0.29[0.772]$ \\
\hline $\log ($ Population $)$ & 9.609 & 9.582 & $0.31[0.753]$ \\
\hline
\end{tabular}

Note: Treated group = municipalities where at least one corruption scandal broke out during the period 1999-2009; Control group = municipalities where no corruption scandal broke out during the same period. 
Table A.5. Differences in means between Treated and Control groups. Contextual variables used in the matching procedure.

Alternative matching procedures

\begin{tabular}{|c|c|c|c|}
\hline & \multicolumn{2}{|c|}{ Mean } & \multirow{2}{*}{$\begin{array}{c}t \text {-test } \\
\text { [p-value] }\end{array}$} \\
\hline & Treated & Control & \\
\hline \multicolumn{4}{|c|}{ (a) One-to-one } \\
\hline \% Turnout & 0.727 & 0.734 & -1.41 [0.159] \\
\hline Income p.c. & 0.946 & 0.941 & $0.68[0.500]$ \\
\hline \% Divorced & 0.026 & 0.025 & 1.69 [0.092] \\
\hline$\%$ College & 0.106 & 0.095 & 3.03 [0.002] \\
\hline \% Unemployment & 0.148 & 0.147 & 0.16 [0.875] \\
\hline Ethnic diversity & 0.060 & 0.054 & 1.58 [0.114] \\
\hline$\%$ Right voters & 0.207 & 0.202 & $1.01[0.314]$ \\
\hline $\log$ (Population) & 9.609 & 9.308 & $3.80[0.000]$ \\
\hline \multicolumn{4}{|c|}{ (b) Kernel } \\
\hline$\%$ Turnout & 0.727 & 0.730 & $-0.50 \quad[0.620]$ \\
\hline Income p.c. & 0.946 & 0.953 & $-0.83[0.406]$ \\
\hline \% Divorced & 0.026 & 0.027 & -1.19 [0.233] \\
\hline$\%$ College & 0.105 & 0.105 & $0.07[0.946]$ \\
\hline \% Unemployment & 0.148 & 0.144 & $0.60[0.547]$ \\
\hline Ethnic diversity & 0.060 & 0.063 & $-0.85[0.397]$ \\
\hline$\%$ Right voters & 0.207 & 0.204 & $0.62[0.538]$ \\
\hline $\log$ (Population) & 9.566 & 9.505 & $0.72[0.472]$ \\
\hline \multicolumn{4}{|c|}{ (c) Radius caliper } \\
\hline$\%$ Turnout & 0.729 & 0.731 & $-0.33[0.741]$ \\
\hline Income p.c. & 0.945 & 0.951 & $\begin{array}{ll}-0.67 & {[0.503]}\end{array}$ \\
\hline \% Divorced & 0.026 & 0.027 & -1.45 [0.148] \\
\hline$\%$ College & 0.104 & 0.102 & $0.45[0.649]$ \\
\hline$\%$ Unemployment & 0.148 & 0.145 & 0.53 [0.597] \\
\hline Ethnic diversity & 0.059 & 0.064 & $-1.23[0.220]$ \\
\hline$\%$ Right voters & 0.207 & 0.203 & 0.70 [0.487] \\
\hline $\log$ (Population) & 9.518 & 9.484 & 0.40 [0.688] \\
\hline
\end{tabular}


Table A.6. Differences in means between Treated and Control groups.

Contextual variables used in the matching procedure. Subsamples.

\begin{tabular}{|c|c|c|c|}
\hline & \multicolumn{2}{|c|}{ Mean } & \multirow{2}{*}{$\begin{array}{c}t \text {-test } \\
\text { [p-value] }\end{array}$} \\
\hline & Treated & Control & \\
\hline \multicolumn{4}{|c|}{ (a) Scandal after the survey? YES } \\
\hline$\%$ Turnout & 0.705 & 0.733 & $1.409[0.163]$ \\
\hline Income p.c. & 0.944 & 0.932 & $1.134 \quad[0.261]$ \\
\hline \% Divorced & 0.028 & 0.027 & $-0.151[0.879]$ \\
\hline$\%$ College & 0.099 & 0.109 & $0.596[0.552]$ \\
\hline \% Unemployment & 0.163 & 0.165 & $-1.071[0.287]$ \\
\hline Ethnic diversity & 0.058 & 0.055 & $-0.187[0.852]$ \\
\hline$\%$ Right voters & 0.513 & 0.540 & $1.036[0.303]$ \\
\hline $\log$ (Population) & 9.338 & 9.161 & $-0.632[0.529]$ \\
\hline \multicolumn{4}{|c|}{ (b) Moving in before the scandal? YES } \\
\hline$\%$ Turnout & 0.735 & 0.725 & $-0.832[0.406]$ \\
\hline Income p.c. & 0.933 & 0.956 & $1.237[0.217]$ \\
\hline \% Divorced & 0.024 & 0.026 & $1.137[0.257]$ \\
\hline$\%$ College & 0.097 & 0.102 & $0.503[0.615]$ \\
\hline \% Unemployment & 0.156 & 0.150 & $-0.420 \quad[0.675]$ \\
\hline Ethnic diversity & 0.056 & 0.055 & $-0.132[0.895]$ \\
\hline$\%$ Right voters & 0.503 & 0.502 & $-0.225[0.821]$ \\
\hline $\log$ (Population) & 9.332 & 9.228 & $-0.564 \quad[0.573]$ \\
\hline \%Residents \& voting at scandal & 0.872 & 0.873 & $-0.017[0.986]$ \\
\hline \multicolumn{4}{|c|}{ (c) Exposed to the scandal? NO } \\
\hline$\%$ Turnout & 0.715 & 0.701 & $-0.835[0.405]$ \\
\hline Income p.c. & 0.952 & 0.946 & $-0.200 \quad[0.841]$ \\
\hline \% Divorced & 0.027 & 0.028 & $0.391[0.693]$ \\
\hline$\%$ College & 0.122 & 0.111 & $-0.781[0.436]$ \\
\hline$\%$ Unemployment & 0.159 & 0.153 & $-0.382[0.703]$ \\
\hline Ethnic diversity & 0.056 & 0.065 & $0.731[0.462]$ \\
\hline$\%$ Right voters & 0.503 & 0.519 & $0.831[0.407]$ \\
\hline $\log$ (Population) & 10.053 & 9.681 & $-1.267 \quad[0.208]$ \\
\hline$\%$ Individuals not exposed & 0.112 & 0.128 & $0.610 \quad[0.543]$ \\
\hline
\end{tabular}


Table A.7: Differences in means between Treated and Control groups. Individual variables obtained from the survey.

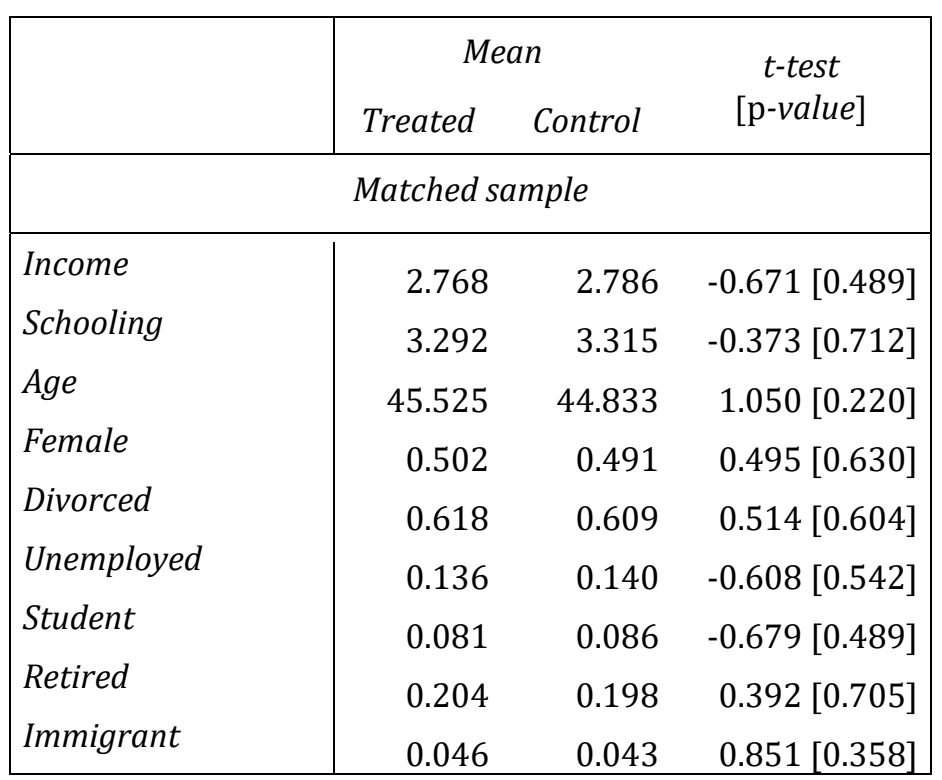

Note: Treated group $=$ municipalities where at least one corruption scandal broke out during the period 1999-2009; Control group = municipalities where no corruption scandal broke out during the same period 
Table A.8: Differences in means between Treated and Control groups. Individual variables obtained from the survey. Subsamples

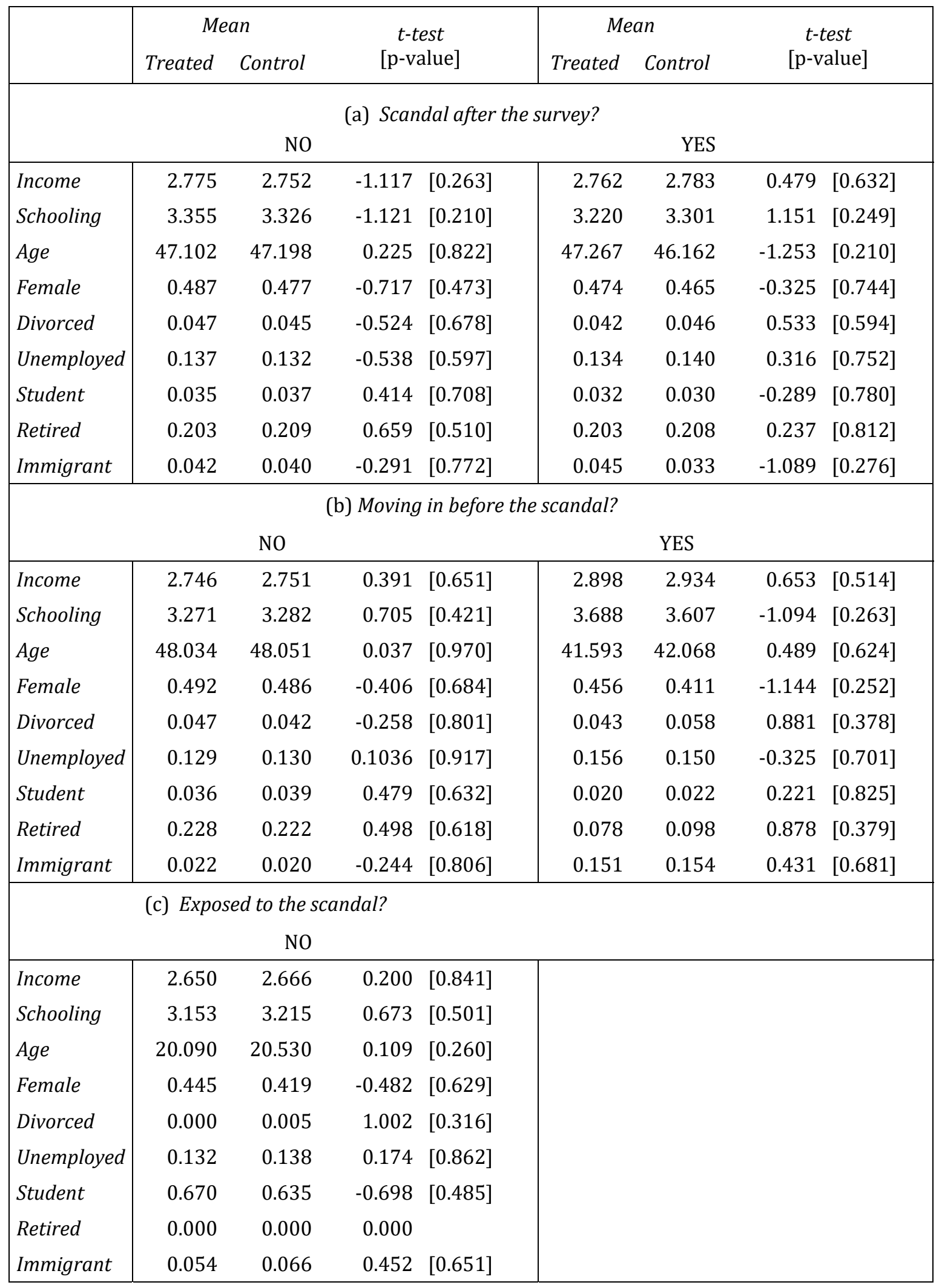


Table A.9: Selective attrition and sorting

\begin{tabular}{|lrrrr|}
\hline \multicolumn{4}{c}{ Mean } & $\begin{array}{c}\text { t-test } \\
\text { [p-value] }\end{array}$ \\
\hline & Moving in after & the scandal? YES & \\
\hline \% Movers & 0.112 & 0.128 & 0.610 & {$[0.543]$} \\
Income & 2.891 & 2.870 & -0.275 & {$[0.783]$} \\
Schooling & 3.502 & 3.583 & -1.021 & {$[0.270]$} \\
Age & 37.012 & 36.083 & 0.225 & {$[0.822]$} \\
Female & 0.503 & 0.463 & -0.325 & {$[0.701]$} \\
Divorced & 0.046 & 0.074 & -1.343 & {$[0.179]$} \\
Unemployed & 0.190 & 0.155 & -1.006 & {$[0.294]$} \\
Student & 0.021 & 0.023 & 0.245 & {$[0.793]$} \\
Retired & 0.068 & 0.088 & 0.972 & {$[0.314]$} \\
Immigrant & 0.061 & 0.063 & 0.891 & {$[0.352]$} \\
\hline
\end{tabular}

Notes:\% Movers: share of individuals moving in after the scandal. The test on individual characteristics considers the information of the individuals moving in the municipality after the scandal.

Table A.10:

Effects of corruption scandals on trust in local politicians. Sensitivity checks

\begin{tabular}{|lccc|}
\hline & Turnout & $\begin{array}{c}\text { Social } \\
\text { capital } \\
\text { (ii) }\end{array}$ & $\begin{array}{c}\text { Corruption } \\
\text { opportunities } \\
\text { (iii) }\end{array}$ \\
\hline Corruption & $-0.236^{* * *}$ & $-0.210^{* * *}$ & $-0.271^{* * *}$ \\
& $(0.075)$ & $(0.075)$ & $(0.079)$ \\
\hline$\% \Delta$ Turnout & YES & NO & NO \\
$\%$ Provincial turnout & YES & NO & NO \\
Newspapers p.c. & NO & YES & NO \\
Associations p.c. & NO & YES & NO \\
$\%$ PPopulation & NO & NO & YES \\
$\%$ Vacation houses & NO & NO & YES \\
Provincial effects & NO & NO & YES \\
\hline
\end{tabular}

Notes: (1) See Table 1. (2) All the regressions include Historical turnout, Contextual variables and Individual variables. (3) Number of observations: 6,902 
Figure A.1: Share of population that identifies corruption and fraud as being among Spain's three main problems

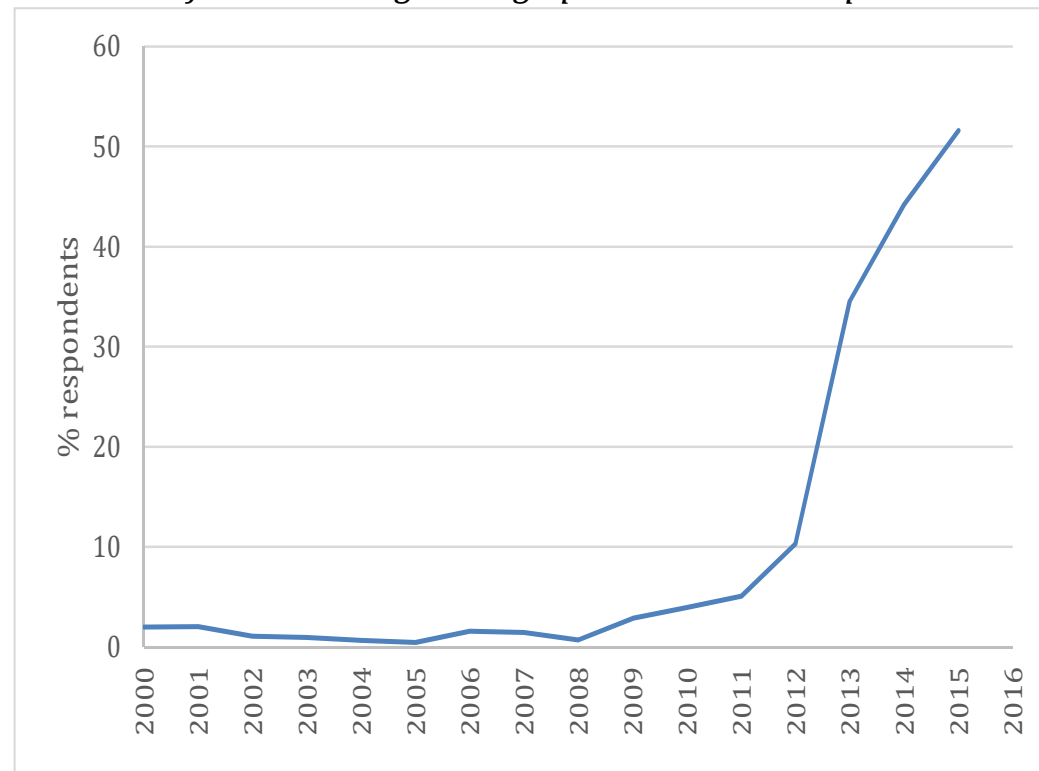

Source: Barometer survey conducted by the CIS ("Centro de Investigaciones Sociológicas"). Findings from the CIS Barometer Survey (March, 2015) corresponding to the multiple-response question in which respondents are asked to identify the three main problems currently affecting Spain.

Figure A.2: Propensity score distribution

\begin{tabular}{|c|c|c|}
\hline & (a) Before matching & (b) After matching \\
\hline & & \\
\hline
\end{tabular}


Figure A.3: Sensitivity analysis.

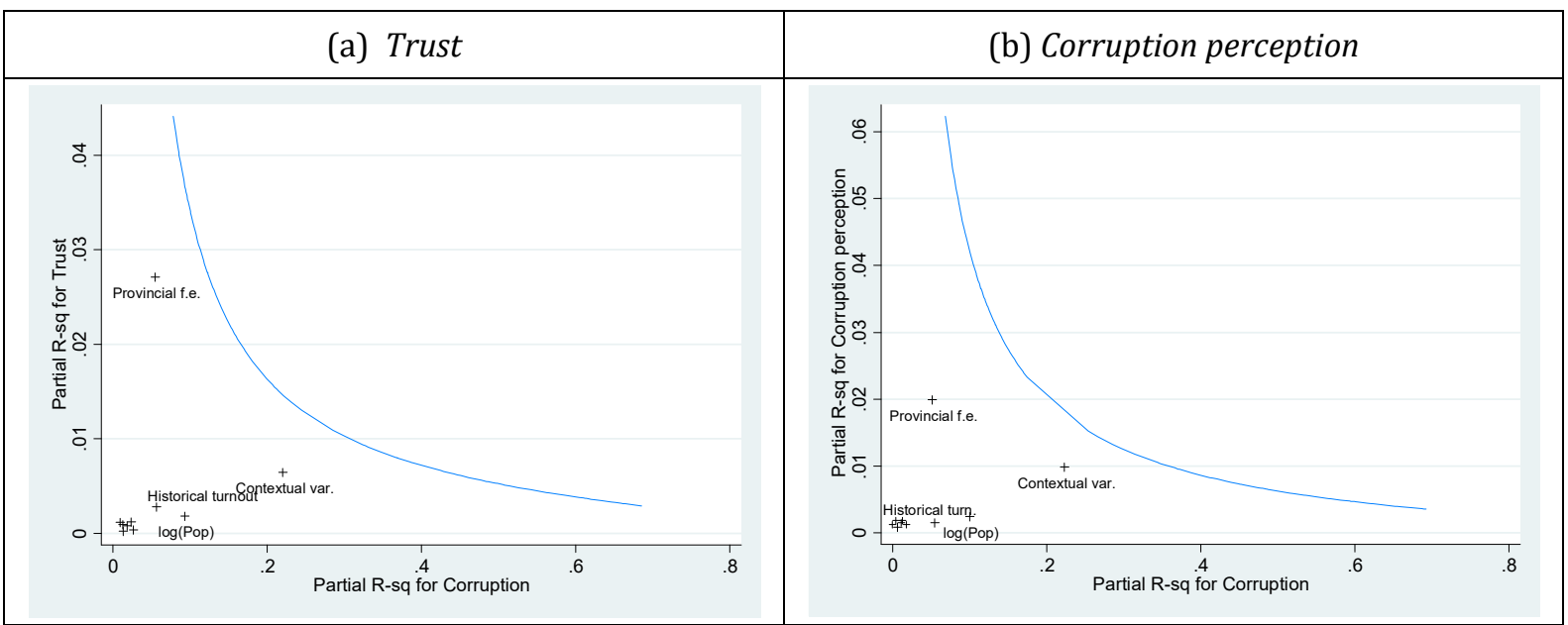

Note: Trust and corruption perception are defined as in columns (vi) and (vii) in Table 1: Trust is equal to 1 if high or medium high trust and 0 otherwise; Corruption perception is equal to one if high or medium high corruption perception and 0 otherwise

Figure A.4: Sensitivity of the mediation analysis.

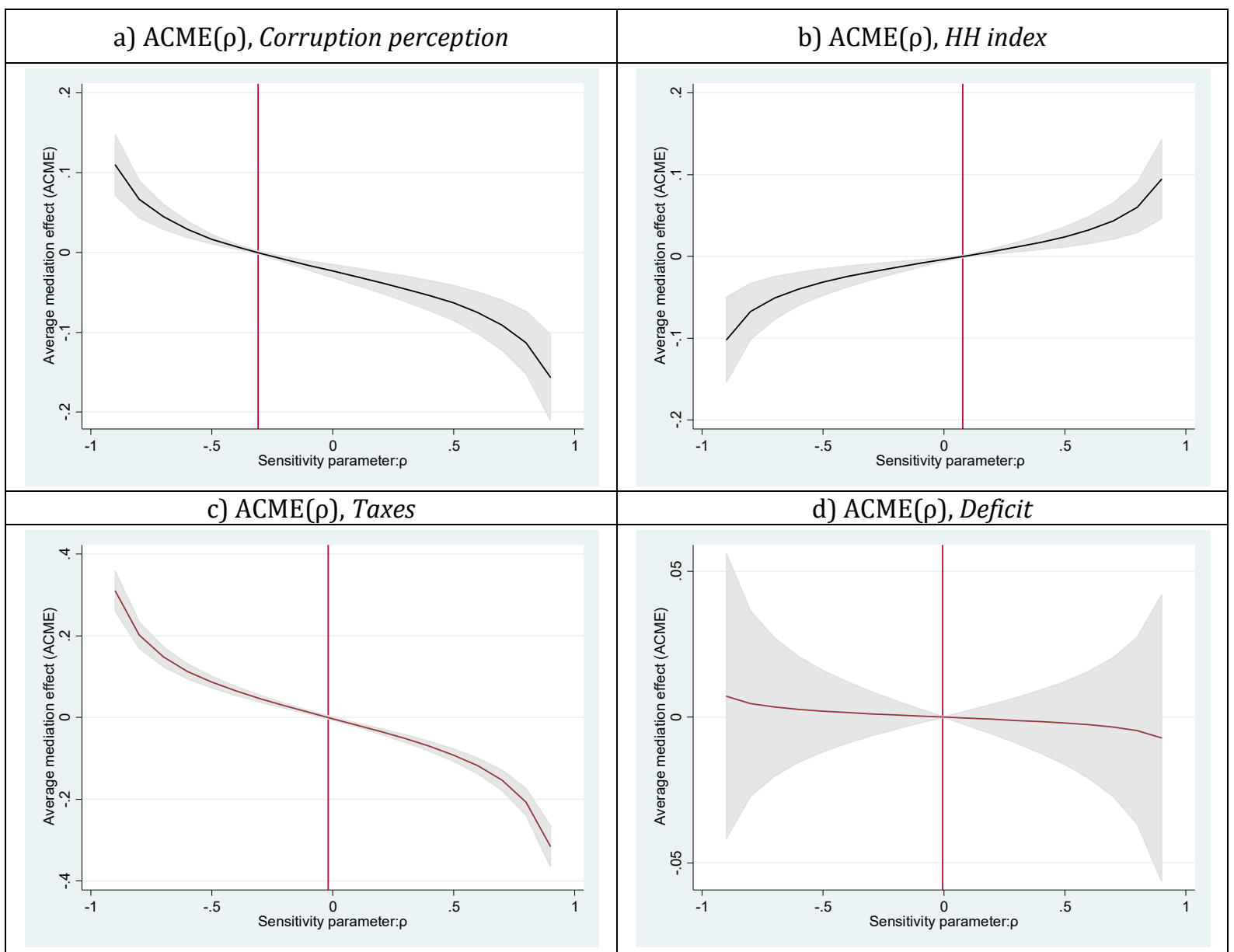

Notes: The black line represents the estimated ACME for different values of the sensitivity parameter $\rho$. The estimates are enclosed by a $95 \%$ confidence interval. The vertical red line is the value of $\rho$ at which the ACME would be zero. 